\title{
Cold-inducible RNA-binding protein as a novel target to alleviate blood-brain barrier damage induced by cardiopulmonary bypass
}

Mingyue Liu, MD, PhD, ${ }^{\text {a }}$ Yongnan Li, MD, PhD, ${ }^{\text {a,b }}$ Yiwei Liu, MD, PhD, ${ }^{\text {a }}$ Shujie Yan, MD, ${ }^{a}$ Gang Liu, MD, ${ }^{\mathrm{a}}$ Qiaoni Zhang, $\mathrm{PhD},{ }^{\mathrm{a}}$ and Bingyang Ji, $\mathrm{MD}, \mathrm{PhD}^{\mathrm{a}}$

\section{ABSTRACT}

Background: Hypothermia provides neuroprotection and alleviates cerebral injury after cardiopulmonary bypass (CPB). The mechanism of cold-inducible RNA-binding protein (CIRP), which has been reported to be facilitated by hypothermia and act as a critical regulatory protein in the brain, remains unclear in CPB. Hence, the role of CIRP on hypothermia CPB-induced brain injury was investigated in a rat model.

Methods: $\mathrm{Cirp}^{-1-}$ rats were generated using the transcription activator-like effector nucleases-based genome editing technique. The animals were randomly allocated to 3 groups ( $\mathrm{n}=5$, each group): sham group, $\mathrm{CPB}$ group, and CPB in Cirp $^{-1-}$ group (Cirp ${ }^{-1-}$ group). Three biological replicates received RNA sequencing in the CPB and $\mathrm{Cirp}^{-1-}$ groups. The relative protein expression of the hippocampus was detected. The integrity of the blood-brain barrier (BBB) was measured using transmission electron microscopy and immunoglobulin $\mathrm{G}$ immunostaining. Glial fibrillary acidic protein in serum was detected. The brain was fixed for histopathological assessment.

Results: More differentially expressed genes of BBB leakage were clustered functionally by gene ontology and Kyoto Encyclopedia of Genes and Genomes pathway analyses. Transforming growth factor- $\beta 1$, matrix metallopeptidase- 9 , tumor necrosis factor- $\alpha$, and malondialdehyde in the hippocampus were higher in the Cirp $^{-/-}$group, whereas the interleukin-4 level was opposite. Furthermore, more serious BBB disruption in the $\mathrm{Cirp}^{-/-}$group was shown using transmission electron microscopy and immunoglobulin G extravasation. Moreover, Cirp $^{-1-}$

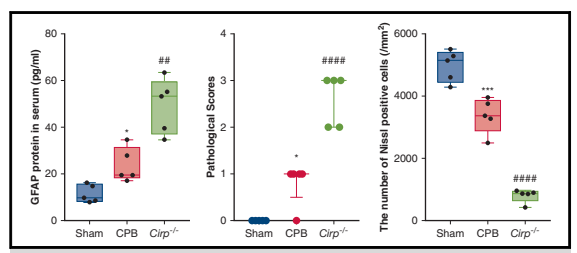

Increased brain injury after CIRP ablation on a rat cardiopulmonary bypass model.

\section{Central Message}

The expression of CIRP increased in the brain during hypothermia CPB, and CIRP exerted an important neuroprotection effect by alleviating $\mathrm{BBB}$ breakdown in hypothermia CPB.

\section{Perspective}

CIRP could be facilitated when temperature decreased to $32^{\circ} \mathrm{C}$ during $\mathrm{CPB}$, and had a neuroprotective effect on brain injury by alleviating BBB leakage, which might be associated with TGF- $\beta 1-$ MMP-9 signals. It would be a novel therapeutic target to prevent CPB-related brain injury.

See Commentary on page 997. showed enhanced tight junction protein degradation and histopathologic injury in the hippocampus (pathological score, surviving hippocampal neurons, and terminal deoxynucleotidyl transferase-mediated $2^{\prime}$-deoxyuridine, $5^{\prime}$-triphosphate nick-end labeling-positive neurons). Therefore, CIRP significantly alleviated neurologic injury.

Conclusions: CIRP exerted important neuroprotective effects by alleviating BBB breakdown, which might be associated with transforming growth factor- $\beta 1$ matrix metallopeptidase-9 signals in hypothermia CPB. (J Thorac Cardiovasc Surg 2019;157:986-96)

From the ${ }^{\mathrm{a} D e p a r t m e n t}$ of Cardiopulmonary Bypass, State Key Laboratory of Cardiovascular Medicine, Fuwai Hospital, National Center for Cardiovascular Disease, Chinese Academy of Medical Science and Peking Union Medical College, Beijing, China; and ${ }^{b}$ Department of Cardiac Surgery, Lanzhou University Second Hospital, Lanzhou University, Lanzhou, China.

This work was supported by the National Natural Science Foundation of China (grants 81270384 and 81470578), and the Graduate Innovation Fund Project of Peking Union Medical College (2017E-CX05)
Received for publication May 17, 2018; revisions received Aug 29, 2018; accepted for publication Aug 29, 2018; available ahead of print Nov 2, 2018.

Address for reprints: Bingyang Ji, MD, PhD, Department of Adult Cardiopulmonary Bypass, Cardiopulmonary Bypass Center, Department of Cardiopulmonary Bypass, Fuwai Hospital, No 167 Beilishi Rd, Xicheng District, 10010 Beijing, China (E-mail: jibingyang@fuwai.com). 0022-5223/\$36.00

Copyright (c) 2018 by The American Association for Thoracic Surgery https://doi.org/10.1016/j.jtcvs.2018.08.100 

Abbreviations and Acronyms
$\mathrm{BBB}=$ blood-brain barrier
cAMP $=$ adenosine $3^{\prime}, 5^{\prime}$-cyclic monophosphate
CIRP = cold-inducible RNA-binding protein
$\mathrm{CPB}=$ cardiopulmonary bypass
DEGs = differentially expressed genes
$\mathrm{GO}=$ gene ontology
$\mathrm{IgG}=$ immunoglobulin $\mathrm{G}$
$\mathrm{IL} \quad=$ interleukin
KEGG = Kyoto Encyclopedia of Genes and Genomes
MDA = malondialdehyde
MMP-9 = matrix metallopeptidase-9
TGF $=$ transforming growth factor
$\mathrm{TNF}=$ tumor necrosis factor
$\mathrm{ZO}=$ zona occludens

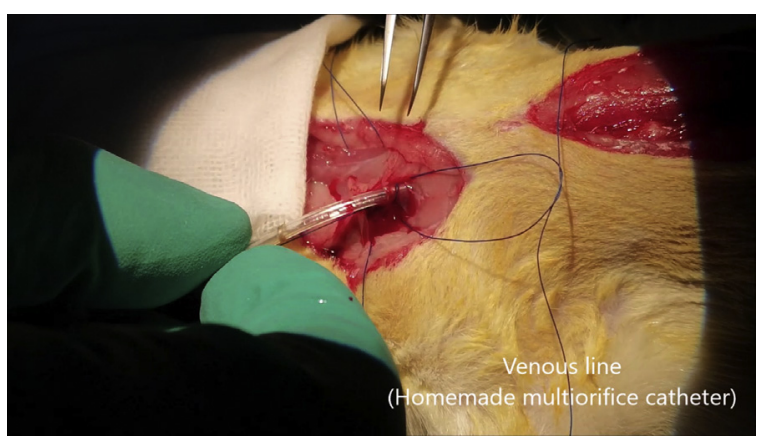

VIDEO 1. Surgical procedure in the rat model of hypothermia cardiopulmonary bypass. Video available at: https://www.jtcvs.org/article/S00225223(18)32495-4/fulltext.

that CIRP plays a leading role in the antiapoptotic effect of hypothermia. ${ }^{8,9}$ Moreover, when CIRP is endogenously induced under hypothermia or artificially overexpressed, hydrogen peroxide-induced neuronal apoptosis is dramatically inhibited, implying the potential neuroprotective role of CIRP. ${ }^{10,11}$

On the basis of this information, it was postulated that CIRP might participate in hypothermia-mediated neuroprotection during $\mathrm{CPB}$. The aim of this study was to show the protective effects of CIRP on BBB leakage induced by hypothermia $\mathrm{CPB}$ in a rat model.

\section{METHODS}

The experimental protocol was approved by the Care of Experimental Animals Committee of the Chinese Academy of Medical Sciences and Peking Union Medical College. All of the experimental procedures were in compliance with the Guide for the Care and Use of Laboratory Animals published by the National Institutes of Health. of the most disturbing outcomes in patients who undergo open heart surgeries, which increases the risk of mortality and postoperative complications. ${ }^{1}$ Because of its high incidence, postoperative cognitive deficits including learning disabilities, memory deficits, hyperactivity, and behavioral disorders bring heavy psychological and economic burden to patients. ${ }^{2}$ Hence, neuroprotection during cardiac surgery is especially important. The neuroprotective effect of hypothermia is mediated by reducing metabolism, relieving cerebral edema, and maintaining the blood-brain barrier (BBB). ${ }^{3,4}$ However, the neuroprotective regulatory mechanism of hypothermia remains unclear.

Cold-inducible RNA-binding protein (CIRP), which was first identified from mouse testis cells, can be facilitated by hypothermia in the brain, heart, and liver. ${ }^{5}$ It is constitutively, but weakly, expressed in various tissues, and is significantly enhanced under hypothermia. ${ }^{5}$ As a critical regulatory protein, CIRP responds to stress such as hypothermia, hypoxia, and ultraviolet light, and transfers from the nucleus to the cytoplasm to activate cell protective reactions. ${ }^{6,7}$ Studies on therapeutic hypothermia of traumatic brain injury and cardiac arrest have suggested

\section{Experimental Animals and Model of CPB}

To study the pathophysiology of CIRP protein in the brain during CPB, genetically engineered rat lines were generated via transcription activatorlike effector nucleases-based genome editing to target exon 3 of Cirp and ablate its expression in intact rats, as previously reported. ${ }^{12}$ Sequencing analysis was also performed to detect base pair deletions and frameshift mutations of Cirp as previously shown. ${ }^{12}$ The following experiments were performed on wild type and $\operatorname{Cirp}^{-1-}$ adult male rats weighing 300 to $400 \mathrm{~g}$. The animals were randomly allocated to 3 groups $(\mathrm{n}=5$, each group): sham group, CPB group, and CPB in $\mathrm{Cirp}^{-1-}$ group $\left(\mathrm{Cirp}^{-1-}\right.$ group).

CPB was performed (Video 1), as previously reported, with minor modifications (Figure 1, A). ${ }^{13,14}$ Briefly, rats were anesthetized with $1.5 \%$ sevoflurane after orotracheal intubation with a 16-gauge cannula (Insyte BD Medical, Sandy, Utah), and mechanically ventilated at 60 breaths per minute $^{-1}$ with $8 \mathrm{~mL} / \mathrm{kg}$ tidal volume (Harvard Apparatus, Holliston, Mass). A 24-gauge catheter was cannulated in the left femoral artery for arterial blood pressure monitoring. CPB was established via the tail artery (cannulated using a 20-gauge catheter) and right external jugular vein-right atrium (cannulated using a homemade multiorificed catheter) after median sternotomy. A 3.5-mm angioplasty balloon catheter, which acted as an endoaortic cross-clamp, was retrogradely inserted into the ascending aorta via the right common carotid artery. In the sham group, rats were anesthetized, cannulated, and heparinized with median sternotomy, but did 

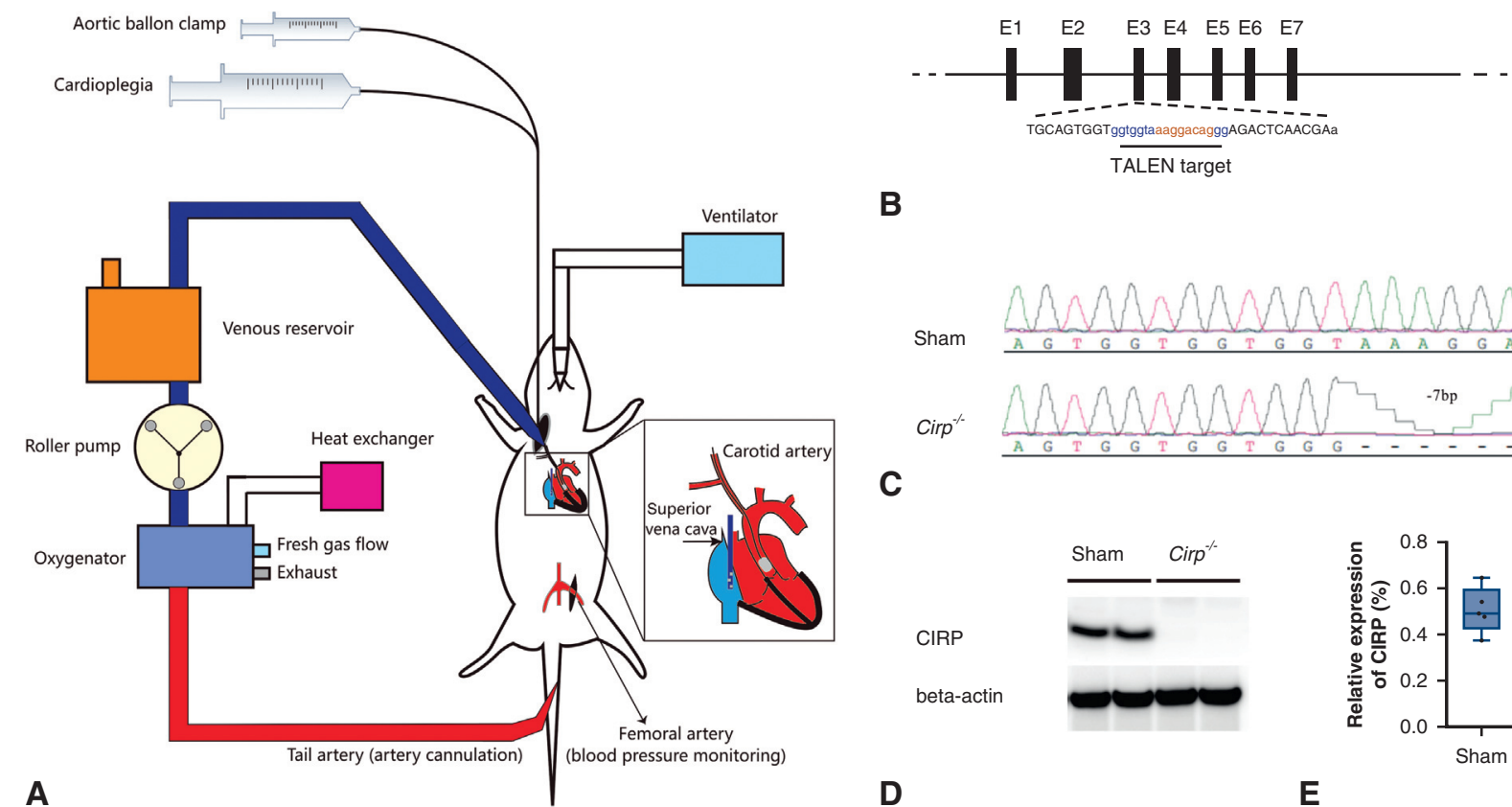

B

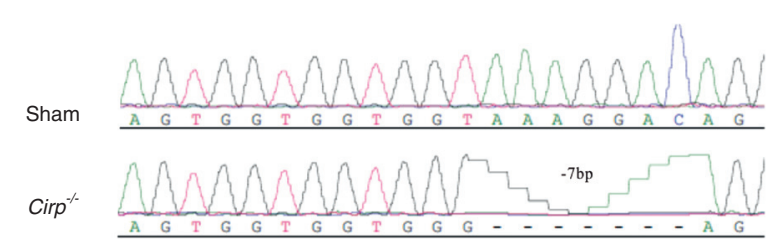

C
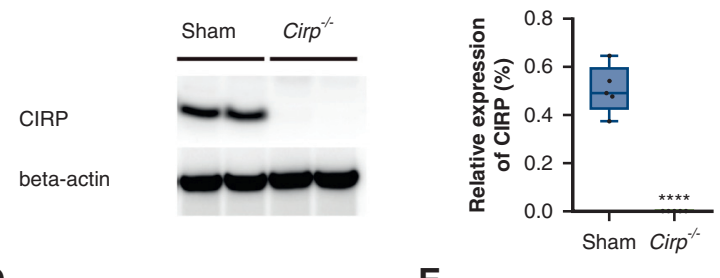

D

E
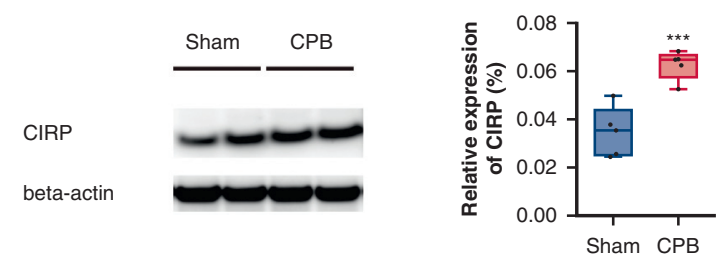

$\mathbf{F}$

G

FIGURE 1. Model of cardiopulmonary bypass and the cerebral expression of cold-inducible RNA-binding protein $(C I R P)$ after cardiopulmonary bypass. A, Schematic overview of the rat cardiopulmonary bypass $(C P B)$ apparatus. B, A schematic diagram of the transcription activator-like effector nucleases (TALEN)-based genome editing strategy applied to generate the $\mathrm{Cirp}^{-1-}$ rats. C, Representative chromatogram showing a microdeletion and representative sequences of mutated alleles identified from clonal amplicons. Black dashes indicate the deleted bases. D and E, The Western blot analysis of CIRP in the hippocampus of wild type and $\operatorname{Cirp}^{-1-}$ rats. $* * * * P<.0001$, between the sham and $\operatorname{Cirp}^{-1-}$ group. F and G, A representative Western blot image showing the CIRP expression between the sham and CPB groups, and the densitometric quantification of CIRP expression. $* * * P<.001$, between the sham and CPB group. The horizontal lines show the 5-number summary, which includes the sample minimum, the lower quartile, the median, the upper quartile, and the sample maximum in the box and whiskers graphs.

not undergo CPB. The entire circuit was primed with $12 \mathrm{~mL} \mathrm{6 \%}$ hydroxyethyl starch (Hextend; Hospira Inc, Lake Forest, Ill), $1 \mathrm{~mL}$ of heparin

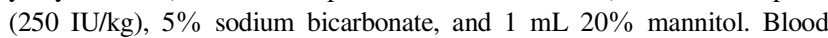
was pumped from a venous reservoir through a custom-designed small-volume oxygenator (Kewei, Beijing, China) using a twin-roller pump (Stöckert, Munich, German). Flow rate was maintained at more than $120 \mathrm{~mL} / \mathrm{kg} / \mathrm{min}$ during CPB. After cooling to a rectal temperature of $32^{\circ} \mathrm{C}$ within 15 minutes, the endoaortic clamp was quickly inflated, while $0.9 \mathrm{~mL}$ St Thomas' solution was concomitantly administered through the central lumen of the angioplasty catheter. Cardioplegic arrest was confirmed using electrocardiography, and the mechanical ventilation was terminated. After 30 minutes of cardioplegic arrest, the balloon was deflated and removed, and mechanical ventilation was restarted. After a 30-minute rewarming, CPB was discontinued, and the animals were maintained, anesthetized with $1.0 \%$ sevoflurane, and ventilated for another 60 minutes, after which rats were sacrificed using decapitation. Arterial blood samples for blood gas analyses were collected just before $\mathrm{CPB}$, before aortic cross-clamping, 30 minutes after aortic cross-clamping, and immediately after the end of CPB.

\section{RNA Sequencing Analyses}

Three biological replicates of each treatment received RNA sequencing. RNA extraction, library preparation for transcriptome sequencing, clustering, sequencing, quality control, transcriptome assembly, gene expression quantification, and bioinformatics analysis were performed, as previously reported. ${ }^{15}$ Briefly, sequencing was performed using an Illumina HiSeq platform (San Diego, Calif), and the raw data in fastq format were processed using in-house Perl scripts. The DESeq R package (version 1.10.1; AT\&T Bell Laboratories, New Zealand) was used to identify differentially expressed genes (DEGs; $P<.05$ ), which were subsequently converted to official gene symbols and grouped according to a common biological property, according to gene ontology (GO) and Kyoto Encyclopedia of Genes and Genomes (KEGG) pathway analyses.

\section{Enzyme-Linked Immunosorbent Assay}

Sixty minutes after CPB termination, blood samples were collected and centrifuged at $3000 \mathrm{rpm}$ for 20 minutes at $4^{\circ} \mathrm{C}$ and the serum was obtained. Glial fibrillary acidic protein concentrations in serum and transforming 


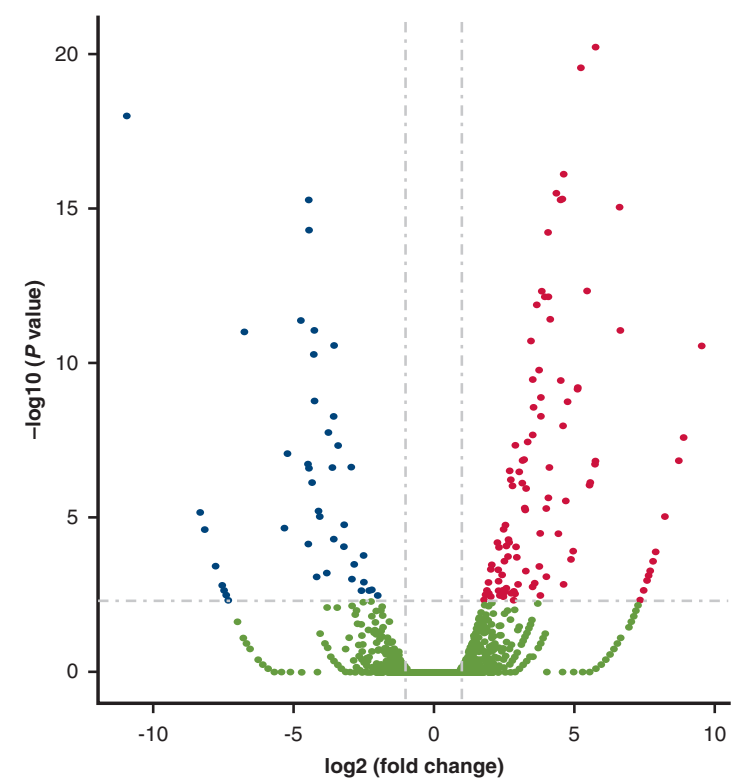

A

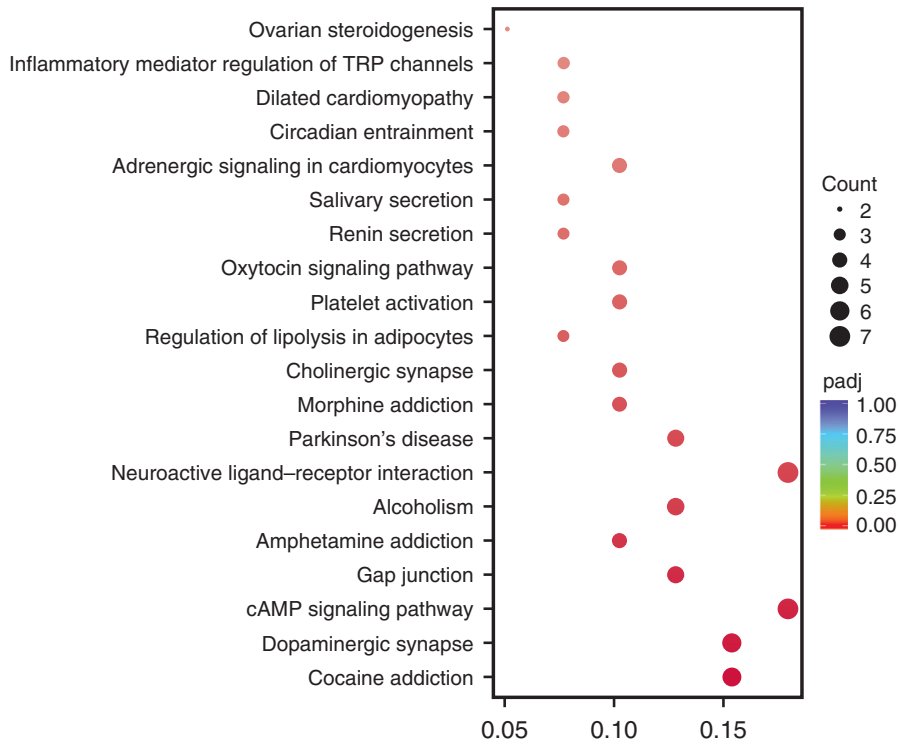

E

FIGURE 2. RNA sequencing analysis of differential gene expression in the hippocampus of wild type and Cirp $^{-/-}$rats after cardiopulmonary bypass. A, Volcano plot of differentially expressed genes $(D E G s)$ between samples. The $X$-axis represents the fold change of DEGs in the different experimental groups. The $-\log 10$ (adjusted $P$ value; padj) in the $Y$-axis shows that DEGs become more significant as the value increases. The dots represent the genes, the green dots indicate nondifferentially expressed genes, the red dots represent the upregulated differentially expressed genes, and the blue dots represent the downregulated differentially expressed genes (Table E2). B, C, and D, The identified genes were functionally clustered by gene ontology $(G O)$ analysis. The GO analysis was conducted at level 2 under the 3 main GO categories including biological process $(B P)$, molecular function $(M F)$, and cellular component $(C C)$. E, The mostly enriched Kyoto Encyclopedia of Genes and Genomes (KEGG) pathway between the cardiopulmonary bypass and Cirp ${ }^{-1-}$ groups. The Y-axis $^{-}$ represents the different KEGG categories, whereas the $X$-axis represents the rich factor. The size of the dot indicates the number of DEGs involved in the pathway. The color bars on the right represent the $P$ value of the KEGG pathway. Each group includes 3 biological duplicates. TRP, Transient receptor potential; $c A M P$, adenosine $3^{\prime}, 5^{\prime}$-cyclic monophosphate.

growth factor (TGF)- $\beta 1$ in hippocampus tissue homogenates were measured using enzyme-linked immunosorbent assay kits from BioSource (Camarillo, Calif), in accordance with the manufacturer's instructions.

\section{Western Blot Analysis}

Equal amounts of protein $(40 \mu \mathrm{g})$ were separated in $4 \%$ to $12 \%$ BisTris gels in a morpholine ethyl sulfonate-sodiumdodecyl sulphate 


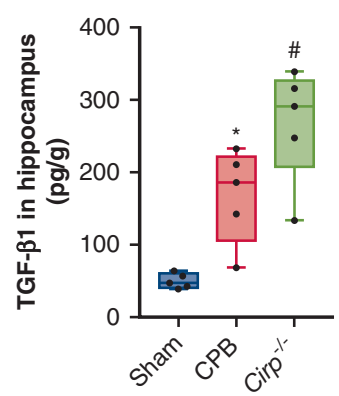

A

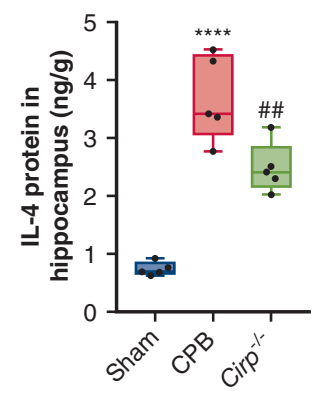

E

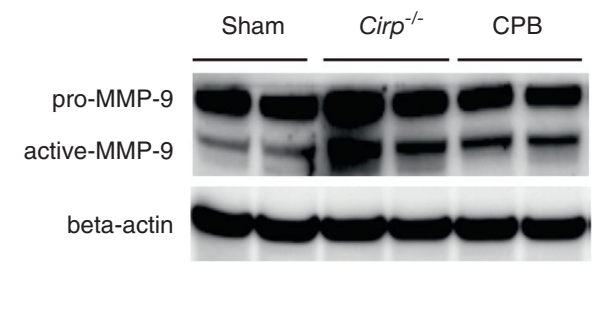

B

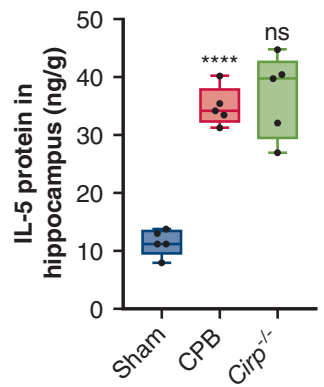

$\mathbf{F}$

G

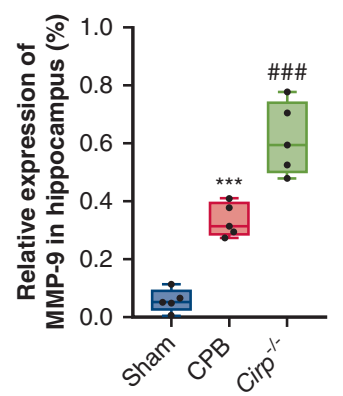

C

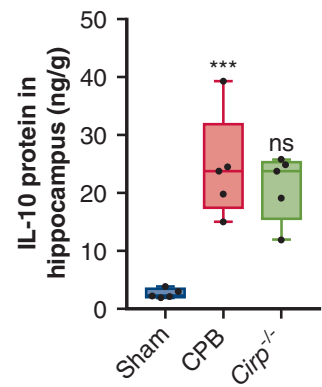

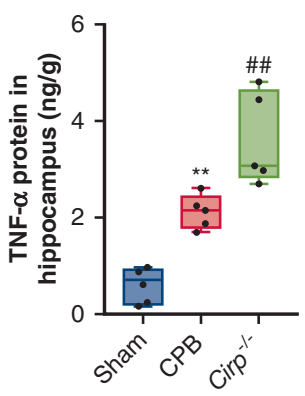

D

FIGURE 3. Cold-inducible RNA-binding protein might be involved in the transforming growth factor (TGF)- $\beta 1$-matrix metallopeptidase $(M M P)-9$ signaling pathway during cardiopulmonary bypass. A, The expression levels of TGF- $\beta 1$ in the hippocampus. B and C, The Western blot images of MMP-9 and the graphic presentation of MMP-9 protein abundance was shown. D-H, The expression levels of tumor necrosis factor (TNF)- $\alpha$, interleukin (IL)-4, IL-5, IL-10, and IL-13 in the hippocampus. **** $P<.0001$, between sham and cardiopulmonary bypass $(C P B)$ group; *** $P<.001$, between sham and CPB group; ${ }^{* *} P<.01$, between sham and CPB group; $* P<.05$, between sham and CPB group; \#\#\#P<.001, between CPB and Cirp ${ }^{-l-}$ group; \#\#P<.01, between CPB and Cirp $^{-1-}$ group; $\# P<.05$, between CPB and Cirp $^{-1-}$ group. The horizontal lines show the 5-number summary, which includes the sample minimum, the lower quartile, the median, the upper quartile, and the sample maximum in the box and whiskers graphs. $n s$, No statistical difference.

running buffer, and were electroblotted onto the nitrocellulose membrane (all obtained from Thermo Fisher Scientific, Waltham, Mass). The nitrocellulose filter membranes were incubated with anti-CIRP (1:1000; ProteinTech, Chicago, Ill), anti-occludin (1:50,000; Abcam, Cambridge, Mass), anti-zona occludens (ZO)-1 (1:1000; ProteinTech), anti-matrix metallopeptidase-9 (MMP-9) (1:500; Aviva Systems Biology, San Diego, Calif), and anti- $\beta$-actin (1:3000; Sigma, St Louis, Mo) at $4^{\circ} \mathrm{C}$ overnight. Then, the membranes were probed with appropriate secondary antibodies conjugated with horseradish peroxides (ZSGB-Bio, Beijing, China). The specific bands of target proteins were visualized by chemiluminescence, and analyzed semiquantitatively with Quantity One system (version 4.6.2; Bio-Rad, Hercules, Calif).

\section{Inflammatory Cytokine Measurement}

Various inflammatory cytokines in hippocampus tissue homogenates were measured using Proinflammatory Panel 2 (rat) kits (K15059D-1) obtained from Meso Scale Discovery (Gaithersburg, Md), according to the manufacturer's protocol. These inflammatory cytokines included tumor necrosis factor- $\alpha$ (TNF- $\alpha$ ), interleukin (IL)-4, IL-5, IL-10, and IL-13.

\section{Transmission Electron Microscopy}

Part of the right hippocampus was fixed with $2.5 \%$ glutaraldehyde and $1 \%$ osmium tetroxide solution. Then, the specimens were dehydrated in ethanol, infiltrated with propylene oxide epoxy, and embedded in epoxy. The ultrathin sections were collected on copper grids and were stained with uranyl acetate and lead citrate. Ultrastructural sections were reviewed and photographed using a transmission electron microscope (TEM-1400plus; JEOL, Tokyo, Japan).

\section{Immunohistochemistry}

BBB disruption was assessed using immunoglobulin $\mathrm{G}$ (IgG) immunostaining, as previously reported. ${ }^{16}$ Briefly, the deparaffinized sections were incubated with biotinylated goat anti-rat $\operatorname{IgG}$ (1:200; Vector Laboratories, Burlingame, Calif) overnight at $4{ }^{\circ} \mathrm{C}$, followed by incubation with an avidin-biotin-horseradish peroxidase complex reagent (1:200, Vector Laboratories) at room temperature for 2 hours. The staining was developed using the $3,3^{\prime}$-diaminobenzidine method. The quantification was performed using ImageJ software (Version 1.51, National Institutes of Health, USA) as previously shown. ${ }^{16}$

\section{Hematoxylin and Eosin and Nissl Staining, and Terminal Deoxynucleotidyl Transferase-Mediated $2^{\prime}$ - Deoxyuridine, $5^{\prime}$-Triphosphate Nick-End Labeling Assay}

Hematoxylin and eosin staining was performed as the standard protocol. Neurologic damage was evaluated according to the following pathological scores: $0=$ no damage; $1=0 \%$ to $12.5 \%$ damage; $2=12.5 \%$ to $25 \%$ damage; $3=25 \%$ to $50 \%$ damage; $4=>50 \%$ damage. ${ }^{17}$ Histologic examination was evaluated by an experienced pathologist with a blind protocol. For Nissl staining, the brain slices were mounted onto slides and stained with $0.2 \%$ Crystal Violet (Sigma-Aldrich, Saint Louis, Mo). To determine apoptosis-like cell death, terminal deoxynucleotidyl transferase-mediated 2'-deoxyuridine, $5^{\prime}$ triphosphate nick-end labeling staining (Promega, Madison, Wis) was performed, according to manufacturer's instructions. 

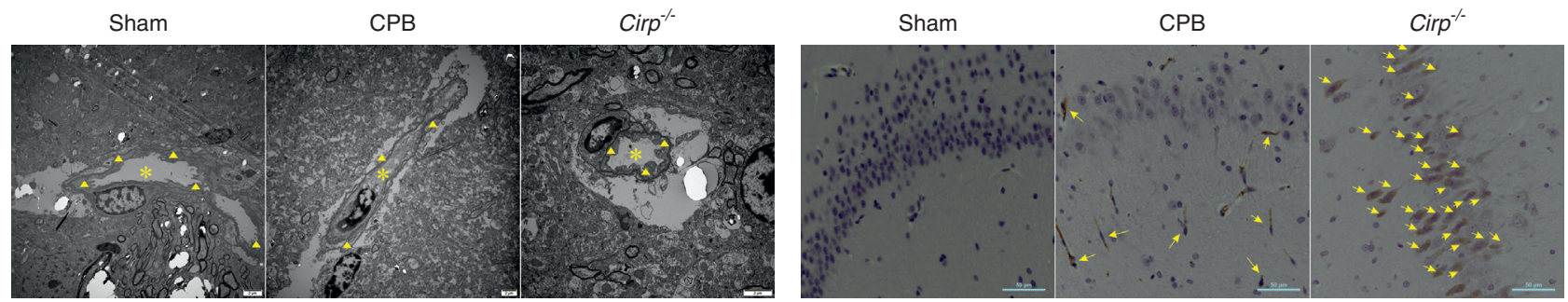

A

B
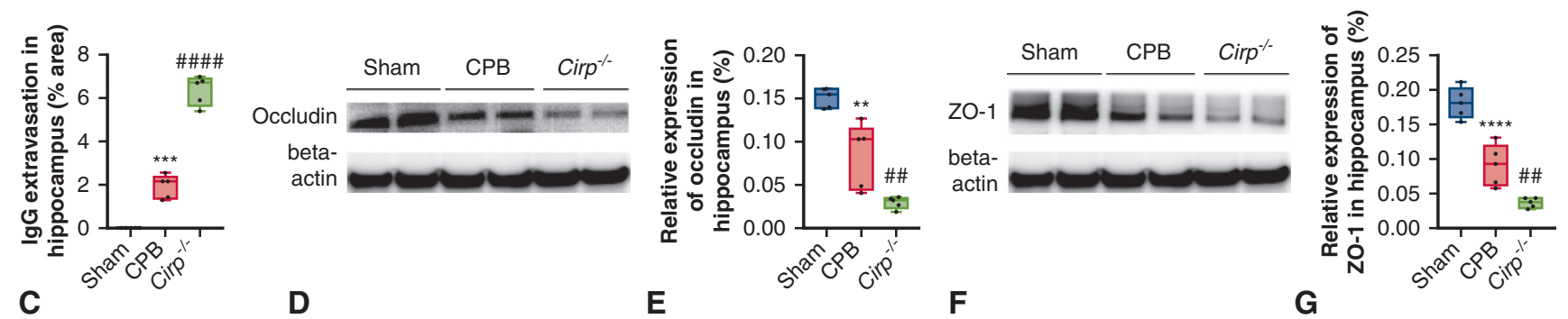

FIGURE 4. Cold-inducible RNA-binding protein maintained the integrity and permeability of the blood-brain barrier during cardiopulmonary bypass. A, Electron microscope examination of the microvasculature in the rat hippocampus. The ultrastructure of the microvasculature showed no alterations in the sham group. Compared with the cardiopulmonary bypass $(C P B)$ group, Cirp $^{-1-}$ induced more obvious interstitial edema around the vessels and more serious destruction of the endothelial compartment. Scale bar $=2 \mu \mathrm{m}$. Triangles indicate microvascular endothelium, and asterisks the capillary lumen. B and C, The representative immunostaining images of immunoglobulin $(I g) \mathrm{G}$ extravasation (arrows, original magnification $40 \times$ ) and graphic presentation of the percentage area with IgG-positive staining in the hippocampus was shown. D and E, The Western blot analysis of occludin in rat hippocampus. $\mathrm{F}$ and $\mathrm{G}$, The Western blot analysis of zona occludens $(Z O)-1$ in rat hippocampus. **** $P<.0001$, between sham and CPB group; *** $P<.001$, between sham and CPB group; ${ }^{* *} P<.01$, between sham and CPB group; \#\#\# $P<.0001$, between CPB and Cirp $^{-1-}$ group; \#\#P $<.01$, between CPB and Cirp ${ }^{-1-}$ group. The horizontal lines show the 5-number summary, which includes the sample minimum, the lower quartile, the median, the upper quartile, and the sample maximum in the box and whiskers graphs.

\section{Malondialdehyde Measurement}

Malondialdehyde (MDA) is a marker of oxidative stress and free oxygen radical-mediated damage. The MDA level of the hippocampus was measured by using an MDA assay kit (ab118970, Abcam), according to manufacturer's instructions.

\section{Statistical Analysis}

Numerical data were expressed as mean \pm standard deviation, and were compared using 1-way analysis of variance followed by StudentNewman-Keuls test. Student $t$ test was used for 2-group analyses. Most of the data sets passed the normality test. The Kruskal-Wallis test was used for nonparametric values, and the Mann-Whitney $U$ test was used as a post-test to identify the specific differences among the groups. Statistical significance was defined as $P<.05$. The data were collected and statistically analyzed using SPSS 16.0 software (SPSS Inc, Chicago, Ill), and all graphs were performed using GraphPad Prism7 (GraphPad Software, La Jolla, Calif).

\section{RESULTS}

\section{Induction of CIRP in Rat Brain After CPB}

With the use of the transcription activator-like effector nucleases-based genome editing technique, Cirp $^{-1-}$ rats were successfully established (Figure 1,B). Sequencing analysis of the targeted Cirp locus revealed a mutation comprising a 7-base pair deletion (Figure 1,C). Western blot analysis verified the gene-targeting efficiency of CIRP, showing a significant reduction in CIRP protein expression $(0.00 \pm 0.00$ vs $0.51 \pm 0.04 ; P<.0001$; Figure $1, D$ and $E)$.
All rats experienced the CPB procedures and full cardioplegic arrest over 30 minutes, and were weaned from CPB without inotropic agents. The physiological data during the operation are summarized in Table E1. The preoperative data in the 3 groups were comparable.

The expression of CIRP protein in the brain of rats between the sham and CPB groups at 1 hour after surgery are shown in Figure 1, $F$. The semiquantitative analysis of Western blot showed that the expression of CIRP protein significantly increased in the CPB group compared with the sham group $(0.06 \pm 0.01$ vs $0.03 \pm 0.01 ; P=.0008$; Figure $1, G)$.

\section{Differential Gene Expression in the Hippocampus of Cirp $^{-/-}$Rats During CPB}

To identify molecules responsible for the increase of CIRP during CPB, RNA sequencing analyses were conducted, and the hippocampal gene expression profiles in CPB and $\mathrm{Cirp}^{-1}$ - group were examined. A total of 148 DEGs were identified $(P<.05$; Figure 2, $A$ and Table E2), and these were functionally clustered by GO (Figure 2, $B-D$ ) and KEGG pathway analyses (Figure 2, E). In the category of biological process of GO functional enrichment analysis (Figure 2, B), concerns were raised that several DEGs were involved in "regulation of blood vessel diameter," "regulation of blood vessel size," and "negative regulation of hydrolase activity," suggesting that the role of CIRP might be related to angiogenic 

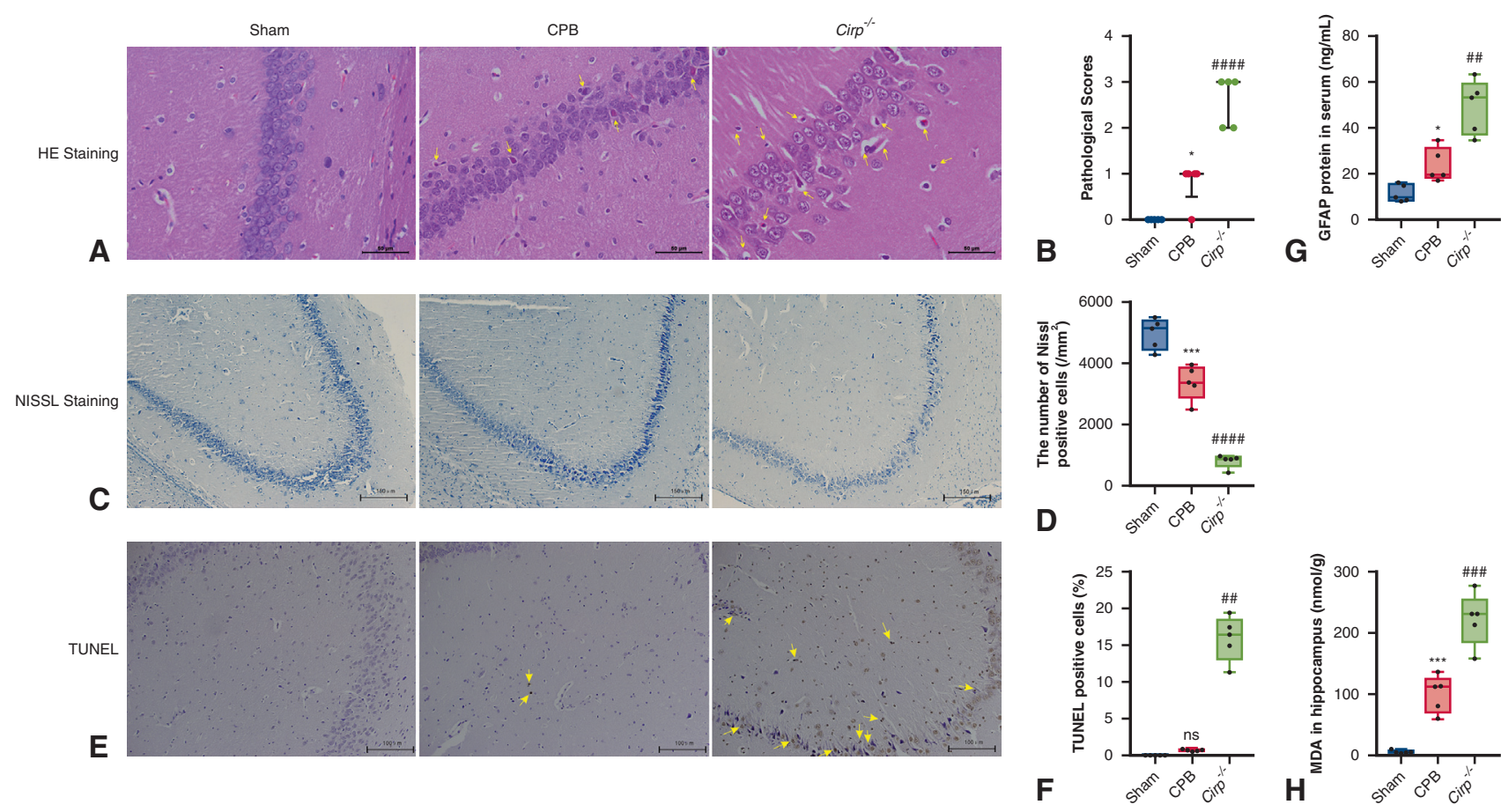

FIGURE 5. Cold-inducible RNA-binding protein alleviated neuronal injury and oxidative stress during cardiopulmonary bypass. A, Ischemic neurons identified using hematoxylin and eosin staining in representative brain sections (arrows, original magnification $40 \times$ ) obtained from rats in each group. No structural alterations were shown in the sham group. $\mathrm{Cirp}^{-1-}$ promoted more ischemic neurons compared with the cardiopulmonary bypass $(C P B)$ group. $\mathrm{B}$, Graphical presentation of the pathological scores. $\mathrm{C}$, In the sham group, the structure of most neurons in the hippocampus was clear, and some uniformly stained Nissl bodies appeared in the cytoplasm. Cirp $^{-/-}$obviously promoted cell loss induced by CPB, compared with the CPB group. D, The number of intact neurons in the hippocampus. E, The terminal deoxynucleotidyl transferase-mediated $2^{\prime}$-deoxyuridine, $5^{\prime}$-triphosphate nick-end labeling (TUNEL) assay performed for the sham group, CPB group, and Cirp $^{-1-}$ group (arrows, original magnification 20×). F, The summary of TUNEL-positive cells at 1 hour after CPB. G, The plasma levels of glial fibrillary acidic protein $(G F A P ; \mathrm{ng} / \mathrm{mL})$. H, Malondialdehyde $(M D A)$ contents in the hippocampus. $* P<.05$, between sham and CPB group; ${ }^{* * *} P<.001$, between sham and CPB group; \#\#P<.01, between CPB and Cirp ${ }^{-l-}$ group; \#\#\# $<.001$, between CPB and Cirp $^{-1-}$ group; \#\#\#P $<.0001$, between CPB and Cirp $^{-1-}$ group. The horizontal lines show the 5-number summary, which includes the sample minimum, the lower quartile, the median, the upper quartile, and the sample maximum in the box and whiskers graphs. $H E$, Hematoxylin and eosin.

molecules and matrix metalloproteinases during $\mathrm{CPB} .{ }^{18}$ As for DEGs enriched in the category of molecular function and cellular components, the results are shown in Figure 2, $C$ and $D$. The KEGG pathway analysis revealed that more DEGs were involved in "adenosine $3^{\prime}, 5^{\prime}$-cyclic monophosphate (cAMP) signaling pathway," "gap junction," and "inflammatory mediator regulation of transient receptor potential channels" (Figure 2,E), which belonged to BBB disruption processing. ${ }^{19-21}$ These results suggest that CIRP ablation in the hippocampus during $\mathrm{CPB}$ was correlated to BBB leakage.

\section{CIRP Might Be Associated With the TGF- $\beta 1-M M P-9$ Signaling Pathway to Maintain the Integrity of the BBB}

According to the prediction of GO and KEGG pathway analyses, the expression of TGF- $\beta 1$ and MMP-9 were examined, which was the common part of the enriched biological process and cAMP-protein kinase A signals. ${ }^{22}$ The expression of TGF- $\beta 1$ and active MMP-9 of hippocampus significantly increased in the $\mathrm{Cirp}^{-/-}$group, compared with the CPB group ( $273 \pm 81$ vs $169 \pm 65$ TGF- $\beta 1$, and $0.62 \pm 0.12$ vs $0.33 \pm 0.06$ active MMP-9; $P=.018$, and $<.001$, respectively; Figure $3, A-C$ ). A similar pattern of changes occurred to TNF- $\alpha$ in the hippocampus $(3.61 \pm 0.96$ vs $2.12 \pm 0.35 ; P=.003$; Figure $3, D)$. In contrast, the production of anti-inflammatory cytokine IL4 significantly decreased in the Cirp $^{-1-}$ group, compared with the CPB group $(2.49 \pm 0.43$ vs $3.69 \pm 0.73$; $P=.002$; Figure $3, E$ ). There were no significant differences in the levels of cytokines IL-5, IL-10, and IL-13 (Figure 3, $F-H$ ) between these 2 groups $(37 \pm 7$ vs $35 \pm 3 \mathrm{IL}-5$, and $21 \pm 6$ vs $25 \pm 9 \mathrm{IL}-10$, and $3.26 \pm 1.09$ vs $3.34 \pm 0.94 \mathrm{IL}-13 ; P=.540, .405$, and .884 , respectively).

Furthermore, the integrity of the BBB was evaluated using transmission electron microscopy, immunohistochemistry, and Western blot analysis to show whether CIRP had a protective effect on BBB leakage. The edema of vascular foot processes and narrowed vascular lumen, which resulted from BBB damage, were observed in wild type 


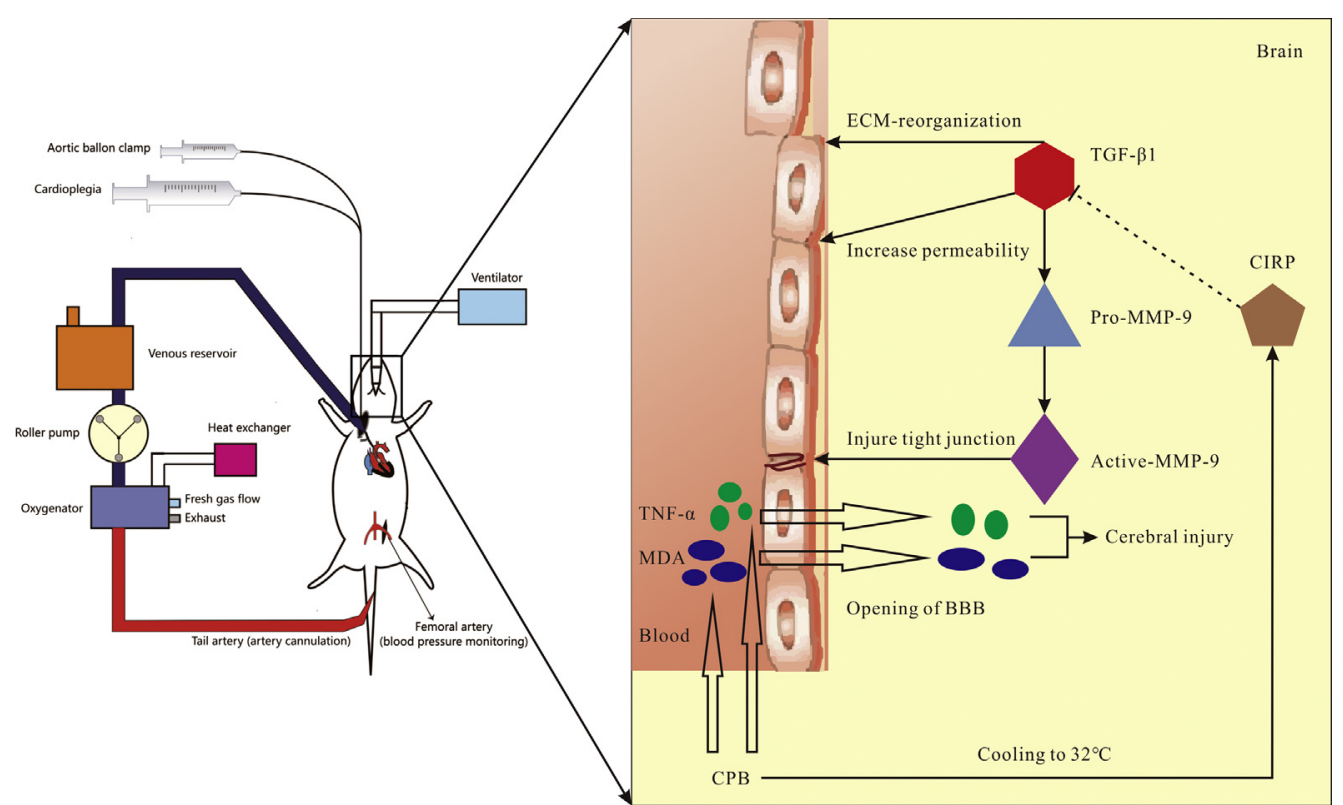

FIGURE 6. The neuroprotective effect on brain injury of cold-inducible RNA-binding protein $(C I R P)$ during cardiopulmonary bypass. The putative role of CIRP responses to cardiopulmonary bypass $(C P B)$-induced brain injury. CIRP could be facilitated when the temperature decreased to $32^{\circ} \mathrm{C}$ during $\mathrm{CPB}$ and might be involved in the transforming growth factor $(T G F)-\beta 1$-matrix metallopeptidase $(M M P)-9$ signaling pathway to alleviate blood-brain barrier $(B B B)$ leakage, which therefore inhibited the release of inflammatory mediator and oxidative stress from the blood, and alleviated cerebral injury during CPB. The arrows indicate the tentative effects of CIRP. ECM, Extracellular matrix; TNF- $\alpha$, tumor necrosis factor- $\alpha$; $M D A$, malondialdehyde.

and Cirp $^{-1-}$ rats after CPB, whereas in the Cirp $^{-1-}$ group, the interstitial edema was obvious around the vessels, and the destruction of the endothelial compartment was more serious and discontinuous (Figure 4, A). Using immunohistochemistry, it was found that $\mathrm{Cirp}^{-1-}$ increased the $\mathrm{IgG}$ extravasation in the hippocampus $(6.36 \pm 0.68$ vs $1.92 \pm 0.54$; $P<.0001$; Figure 4, $B$ and $C$ ). Western blot analysis results also confirmed that the tight junction protein levels of occludin and ZO-1 decreased after $\mathrm{CPB}$, compared with the sham group, and Cirp ablation could effectively accelerate these decreasing trends $(0.03 \pm 0.01$ vs $0.08 \pm 0.04$ occludin, and $0.04 \pm 0.01$ vs $0.09 \pm 0.03 \mathrm{ZO}-1 ; P=.007$, and .0058 , respectively; Figure $4, D-G$ ). These results were consistent with the KEGG pathway analysis, and suggested the possible role of CIRP in maintaining the integrity of the BBB during CPB.

\section{CIRP Alleviated Neuronal Injury and Oxidative Stress During CPB}

Ischemic neuronal change was identified in the CA1 section of the hippocampus. In the sham group, neurons were morphologically intact with a clear shape and abundant cytoplasm. In the $\mathrm{Cirp}^{-1-}$ and CPB groups, ischemic neurons exhibited shrunken cell bodies, triangulated pyknotic nuclei, and eosinophilic cytoplasm. The pathological score of the $\mathrm{Cirp}^{-1-}$ group was higher than that of the CPB group (3.0 [interquartile range, 2.0-3.0] vs 1.0 [interquartile range, 0.5-1.0], $P<.0001$; Figure 5, $A$ and $B$ ). Nissl staining revealed remarkable neuron loss in Cirp $^{-1-}$ rats (Figure 5, C). The deficiency of CIRP robustly increased neuron loss $(802 \pm 216$ vs $3369 \pm 564 ; P<.0001$; Figure $5, D$ ). The number of terminal deoxynucleotidyl transferase-mediated 2'-deoxyuridine, $\quad 5^{\prime}$-triphosphate nick-end labeling-positive cells was significantly increased in the Cirp $^{-, /}$group, compared with the CPB group $(15.98 \pm 3.05$ vs $0.70 \pm 0.14 ; P=.0012$; Figure $5, E$ and $F$ ). In addition, glial fibrillary acidic protein levels, a cerebral injury marker in plasma, were significantly higher in $\mathrm{Cirp}^{-/-}$rats, compared with wild type rats ( $49 \pm 12$ vs $24 \pm 7 ; P=.0011$; Figure $5, G)$, indicating that CIRP deficiency was associated with more serious brain cellular injury during CPB. Moreover, MDA levels were significantly elevated in the Cirp $^{-1-}$ group, compared with the CPB group $(223 \pm 43$ vs $101 \pm 30 ; P=.0001$; Figure 5, $H$ ).

\section{DISCUSSION}

In the present study, the role of CIRP responses to CPBinduced brain injury was shown, to our knowledge, for the first time. The results revealed that $\mathrm{Cirp}^{-1-}$ was associated with aggravated cerebral injury in rats after 75-minute CPB, as evidenced by significantly increased hippocampal neuronal loss and local brain oxidative stress damage. The present results also suggest that Cirp ablation exacerbated the BBB leakage and aggravated the inflammatory responses of the brain, as predicted by RNA sequencing 


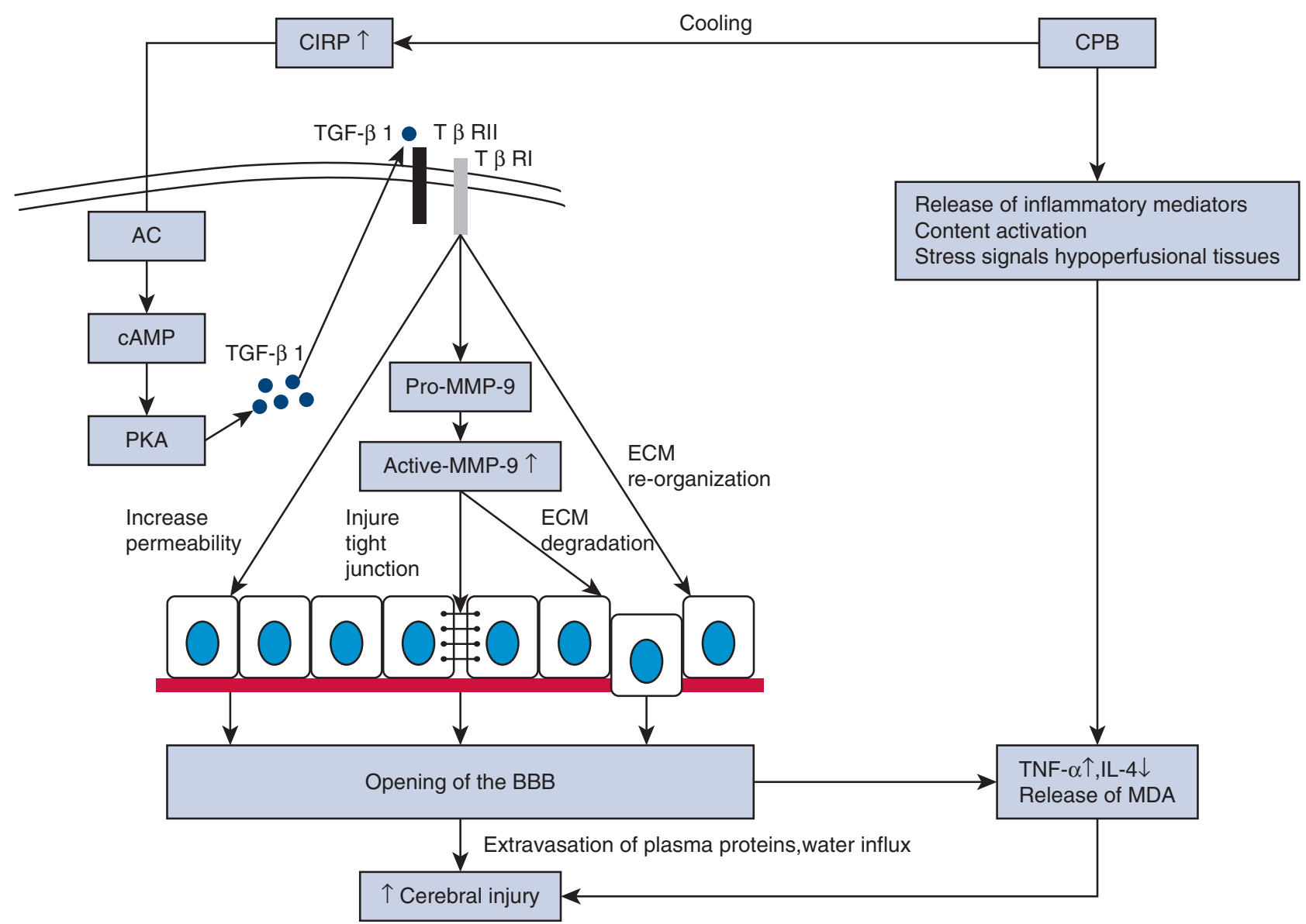

FIGURE 7. Putative mechanisms for how cold-inducible RNA-binding protein $(C I R P)$ prevents brain injury induced by cardiopulmonary bypass $(C P B)$. The arrows indicate the tentative effects of CIRP. TGF- $\beta 1$, Transforming growth factor- $\beta 1 ; T \beta R I I$, transforming growth factor $\beta$ receptor II; T $\beta R I$, transforming growth factor $\beta$ receptor I; $A C$, adenyl cyclase; $c A M P$, adenosine $3^{\prime}, 5^{\prime}$-cyclic monophosphate; $P K A$, protein kinase A; $M M P$-9, matrix metallopeptidase-9; $E C M$, extracellular matrix; $B B B$, blood-brain barrier; $T N F-\alpha$ : tumor necrosis factor- $\alpha$; $I L-4$, interleukin-4; $M D A$, malondialdehyde.

analyses, which might be associated with the TGF- $\beta 1-$ MMP-9 pathway. The neuroprotective effect of CIRP is summarized in Figure 6.

An increasing number of studies have reported on the incidence of CPB-induced brain injury, in which the molecular mechanism remains unclear. ${ }^{2}$ Because of its cytoprotective effect, hypothermia has been widely applied in cardiac surgery. ${ }^{23,24}$ Previous studies on the molecular biological mechanisms of hypothermia during CPB mainly focused on its role on metabolism reduction. However, the precise mechanism remains undetermined. When the body temperature declines, various proteins are induced to accommodate to the temperature change. CIRP is the first cold-shock protein expressed in mammalian cells. ${ }^{5}$ It has a regulatory effect on cell growth and apoptosis under cold induction. CIRP mRNA could be found in great quantities at low temperatures, but it could hardly be detected at normal temperatures, indicating that the stability of CIRP mRNA is regulated by temperature. ${ }^{25}$ Furthermore, hypothermia after cerebral ischemia/reperfusion injury can promote the production of CIRP. ${ }^{26}$ The molecular characteristics of CIRP encouraged the investigators to verify the neuroprotective effect of CIRP against CPB-related brain injury.

In the present study, it was found that CIRP was significantly elevated in the hippocampus after hypothermic CPB. This result was consistent with previous studies, which suggested that hypothermia, hypoxia, and inflammation might be involved in the upregulation of CIRP, serving as the response of neurons to ischemia. ${ }^{26}$ To further explore the regulatory mechanism of CIRP, gene expression differences were compared between wild type and Cirp $^{-1-}$ rats after $\mathrm{CPB}$. According to the KEGG analysis, the enriched signals of "cAMP signaling pathway," "gap junction," and "inflammatory mediator regulation of transient receptor potential channels" were noteworthy, because all of these participated in BBB disruption, ${ }^{19-21}$ which was the focus of concern in this study.

Although the mechanisms of cerebral injury after CPB are not fully understood, injury to BBB leakage has been 
regarded as a crucial part in the pathophysiological process. ${ }^{27} \mathrm{BBB}$ disruption occurred in $67 \%$ of patients who undergo open heart surgery, ${ }^{28}$ and Jonas and colleagues reported that an increase in permeability of the BBB might be a sign and a mechanism of brain damage in the piglet model of $\mathrm{CPB}^{29}$ Prolonged $\mathrm{CPB}$ time stimulates a neutrophil-mediated decrease in $\beta$-catenin expression in cerebral microvascular endothelial cells, ${ }^{30}$ suggesting that CPB-induced BBB leakage could injure the brain by exposing it to harmful substances otherwise confined to the vasculature. ${ }^{31}$ Therefore, the prevention of BBB disruption might alleviate cerebral injury after CPB. In the present study, the investigators attempted to propose a new target for hypothermia CPB associated with the maintenance of BBB integrity.

According to RNA sequencing analyses, the TGF- $\beta 1$ pathway, as part of the cAMP-protein kinase A signals, might be involved in the regulation between CIRP and the BBB during CPB. The TGF- $\beta 1$ pathway was related to brain injury. ${ }^{32} \mathrm{As}$ an angiogenic and profibrogenic factor, TGF- $\beta 1$ induced the expression and deposition of extracellular matrix components, and eventually resulted in communicating hydrocephalus by increasing endothelial permeability and decreasing ion and fluid transport. ${ }^{33}$ Furthermore, as an upstream signal-regulated molecule, TGF- $\beta 1$ induced MMP-9 expression in cultured human meningeal cells. ${ }^{34}$ MMP-9 was a major gelatinase and collagenase, and was known to participate in the breakdown of the BBB under pathological conditions, such as brain ischemia and hydrocephalus. ${ }^{35}$ MMP-9 degraded fibronectin and collagen-extracellular matrix components generated through the TGF- $\beta 1$ signaling pathway ${ }^{36}$ and enhanced BBB permeability via brain endothelial cell disruption. ${ }^{37}$ By verifying the predictive molecule from RNA sequencing analyses, the expression of TGF- $\beta 1$ and active MMP-9 of hippocampus increased in the Cirp $^{-1-}$ group during CPB. These results, together with the high TNF- $\alpha$ and low IL-4 levels in the hippocampus in the $\operatorname{Cirp}^{-/-}$group, suggested that CIRP might be associated with the TGF- $\beta 1$-MMP-9 signaling pathway, which alleviated the disruption of the $\mathrm{BBB}$, as confirmed by the decrease in tight junction protein levels and increase in permeability to IgG when Cirp was knockout during $\mathrm{CPB}$. As a result, the BBB leakage promoted the release of the inflammatory mediator TNF- $\alpha$ from the blood and inhibited the expression of antiinflammatory cytokine IL-4 in the brain. Thus, CPBinduced BBB disruption might be closely associated with the reduced expression of CIRP. The proposed mechanism as to how CIRP might attenuate the BBB leakage induced by $\mathrm{CPB}$ is summarized in Figure 7.

Neuronal damage continued to exist although CIRP was induced under hypothermia $\mathrm{CPB}$. The explanation might be that the increased expression of CIRP after CPB could attenuate, but not reverse, the injury under physiopathologic conditions. Thus, exogenous CIRP supplement might become a novel therapeutic target in the prevention of brain injury caused by CPB. However, besides CPB, the pathophysiology of brain injury during open heart surgery is multifactorial. Initiated by major surgery and regulated by neuroendocrine activation, intraoperative formation of gaseous emboli and aggregated platelets, systemic inflammatory response, hypoperfusion, hypotension, surgical trauma, and blood loss all enhance the risk of cerebral injury. ${ }^{38}$ Therefore, the expression and function of CIRP cannot be explained simply by a single mechanism during CPB. Nevertheless, the present study revealed a new endogenous mechanism for maintaining BBB integrity under hypothermia CPB.

There were several limitations that merit comment in the present study. First, it was difficult for rats to survive after median thoracotomy with great invasion in the present study. To explore the effect of CIRP on postoperative behavior predicted by GO functional enrichment analysis, a functional experiment needs to be conducted with improving the model in the follow-up study. Second, further investigation is needed to identify the specific messenger molecules of CIRP, to modulate the TGF- $\beta 1$-MMP-9 signaling pathway. Last, potential differences in the nervous systems of humans and rodents, and clinical settings, such as the major surgery that was not present in our model, were not examined and should be further investigated.

\section{CONCLUSIONS}

These present findings showed that the expression of CIRP increased in the brain after cooling to $32^{\circ} \mathrm{C}$ during $\mathrm{CPB}$, and that CIRP exerted an important neuroprotective effect by alleviating BBB breakdown, which might be associated with TGF- $\beta 1$-MMP-9 signals in a rat model of hypothermia CPB.

\section{Conflict of Interest Statement}

Authors have nothing to disclose with regard to commercial support.

The authors thank Dr Hao Zhang for assistance with genetically engineered rats and Dr Bing Gong for excellent editorial assistance. Mingyue Liu especially wishes to thank Chenyu Hua, whose songs have encouraged her over the past 5 years.

\section{References}

1. Salameh A, Dhein S, Dähnert I, Klein N. Neuroprotective strategies during cardiac surgery with cardiopulmonary bypass. Int J Mol Sci. 2016;17:E1945.

2. Su XW, Undar A. Brain protection during pediatric cardiopulmonary bypass. Artif Organs. 2010;34:91-102.

3. Bruggemans EF. Cognitive dysfunction after cardiac surgery: pathophysiological mechanisms and preventive strategies. Neth Heart J. 2013;21:70-3.

4. Idris Z, Zenian MS, Muzaimi M, Hamid WZ. Better Glasgow outcome score, cerebral perfusion pressure and focal brain oxygenation in severely traumatized brain following direct regional brain hypothermia therapy: a prospective randomized study. Asian J Neurosurg. 2014;9:115-23. 
5. Kaneko T, Kibayashi K. Mild hypothermia facilitates the expression of coldinducible RNA-binding protein and heat shock protein 70.1 in mouse brain. Brain Res. 2012;1466:128-36.

6. De Leeuw F, Zhang T, Wauquier C, Huez G, Kruys V, Gueydan C. The coldinducible RNA-binding protein migrates from the nucleus to cytoplasmic stress granules by a methylation-dependent mechanism and acts as a translational repressor. Exp Cell Res. 2007;313:4130-44.

7. Wellmann S, Bührer C, Moderegger E, Zelmer A, Kirschner R, Koehne P, et al Oxygen-regulated expression of the RNA-binding proteins RBM3 and CIRP by a HIF-1-independent mechanism. J Cell Sci. 2004;117:1785-94.

8. Wang G, Zhang JN, Guo JK, Cai Y, Sun HS, Dong K, et al. Neuroprotective effects of cold-inducible RNA-binding protein during mild hypothermia on traumatic brain injury. Neural Regen Res. 2016;11:771-8.

9. Wu L, Sun HL, Gao Y, Hui KL, Xu MM, Zhong H, et al. Therapeutic hypothermia enhances cold-inducible RNA-binding protein expression and inhibits mitochondrial apoptosis in a rat model of cardiac arrest. Mol Neurobiol. 2017;54:2697-705.

10. Li S, Zhang Z, Xue J, Liu A, Zhang H. Cold-inducible RNA binding protein inhibits H2O2-induced apoptosis in rat cortical neurons. Brain Res. 2012;1441:47-52.

11. Liu J, Xue J, Zhang H, Li S, Liu Y, Xu D, et al. Cloning, expression, and purification of cold inducible RNA-binding protein and its neuroprotective mechanism of action. Brain Res. 2015;1597:189-95.

12. Li J, Xie D, Huang J, Lv F, Shi D, Liu Y, et al. Cold-inducible RNA-binding protein regulates cardiac repolarization by targeting transient outward potassium channels. Circ Res. 2015;116:1655-9.

13. de Lange F, Yoshitani K, Podgoreanu MV, Grocott HP, Mackensen GB. A novel survival model of cardioplegic arrest and cardiopulmonary bypass in rats: a methodology paper. J Cardiothorac Surg. 2008;3:51.

14. Zhu X, Ji B, Liu J, Sun Y, Wu S, Zheng Z, et al. Establishment of a novel rat model without blood priming during normothermic cardiopulmonary bypass. Perfusion. 2014;29:63-9.

15. Cao S, Zhu L, Nie H, Yin M, Liu G, Yan X. De novo assembly, gene annotation, and marker development using Illumina paired-end transcriptome sequencing in the Crassadomagigantea. Gene. 2018;658:54-62.

16. He HJ, Wang Y, Le Y, Duan KM, Yan XB, Liao Q, et al. Surgery upregulates high mobility group box-1 and disrupts the blood-brain barrier causing cognitive dysfunction in aged rats. CNS Neurosci Ther. 2012;18:994-1002.

17. Shen L, Wang J, Liu K, Wang C, Wang C, Wu H, et al. Hydrogen-rich saline is cerebroprotective in a rat model of deep hypothermic circulatory arrest. Neurochem Res. 2011;36:1501-11.

18. Davis GE, Senger DR. Endothelial extracellular matrix: biosynthesis, remodeling, and functions during vascular morphogenesis and neovessel stabilization. Circ Res. 2005;97:1093-107.

19. Yang B, Wang S, Yu S, Chen Y, Li L, Zhang H, et al. C1q/tumor necrosis factorrelated protein 3 inhibits oxidative stress during intracerebral hemorrhage via PKA signaling. Brain Res. 2017;1657:176-84.

20. Li MW, Mruk DD, Cheng CY. Gap junctions and blood-tissue barriers. Adv Exp Med Biol. 2012;763:260-80.

21. Corrigan F, Mander KA, Leonard AV, Vink R. Neurogenic inflammation after traumatic brain injury and its potentiation of classical inflammation. J Neuroinflammation. 2016;13:264.

22. Weng L, Wang W, Su X, Huang Y, Su L, Liu M, et al. The Effect of cAMP-PKA activation on TGF- $\beta 1$-induced profibrotic signaling. Cell Physiol Biochem. 2015; 36:1911-27.
23. Mora CT, Henson MB, Weintraub WS, Murkin JM, Martin TD, Craver JM, et al The effect of temperature management during cardiopulmonary bypass on neurologic and neuropsychologic outcomes in patients undergoing coronary revascularization. J Thorac Cardiovasc Surg. 1996;112:514-22.

24. Okano N, Owada R, Fujita N, Kadoi Y, Saito S, Goto F. Cerebral oxygenation is better during mild hypothermic than normothermic cardiopulmonary bypass. Can J Anaesth. 2000;47:131-6.

25. Oishi K, Yamamoto S, Uchida D, Doi R. Ketogenic diet and fasting induce the expression of cold-inducible RNA-binding protein with time-dependent hypothermia in the mouse liver. FEBS Open Bio. 2013;3:192-5.

26. Nishiyama H, Itoh K, Kaneko Y, Kishishita M, Yoshida O, Fujita J. A glycinerich RNA-binding protein mediating cold-inducible suppression of mammalian cell growth. J Cell Biol. 1997;137:899-908.

27. Abrahamov D, Levran O, Naparstek S, Refaeli Y, Kaptson S, Abu Salah M, et al. Blood-brain barrier disruption after cardiopulmonary bypass: diagnosis and correlation to cognition. Ann Thorac Surg. 2017;104:161-9.

28. Merino JG, Latour LL, Tso A, Lee KY, Kang DW, Davis LA, et al. Blood brain barrier disruption after cardiac surgery. Am J Neuroradiol. 2013;34:518-23.

29. Okamura T, Ishibashi N, Kumar TS, Zurakowski D, Iwata Y, Lidov HG, et al Hypothermic circulatory arrest increases permeability of the blood brain barrier in watershed areas. Ann Thorac Surg. 2010;90:2001-8.

30. Schuller AM, Windolf J, Blaheta R, Cinatl J, Kreuter J, Wimmer-Greinecker G, et al. Degradation of microvascular brain endothelial cell beta-catenin after coculture with activated neutrophils from patients undergoing cardiac surgery with prolonged cardiopulmonary bypass. Biochem Biophys Res Commun. 2005;329:616-23.

31. Roach GW, Kanchuger M, Mangano CM, Newman M, Nussmeier N, Wolman R, et al. Adverse cerebral outcomes after coronary bypass surgery. Multicenter study of Perioperative Ischemia Research Group and the Ischemia Research and Education Foundation Investigators. N Engl J Med. 1996;335:1857-63.

32. Buckwalter MS, Wyss-Coray T. Modelling neuroinflammatory phenotypes in vivo. $J$ Neuroinflammation. 2004:1:10.

33. Pittet JF, Griffiths MJ, Geiser T, Kaminski N, Dalton SL, Huang X, et al. TGFbeta is a critical mediator of acute lung injury. J Clin Invest. 2001;107:1537-44.

34. Okamoto T, Takahashi S, Nakamura E, Nagaya K, Hayashi T, Fujieda K. Transforming growth factor-betal induces matrix metalloproteinase-9 expression in human meningeal cells via ERK and Smad pathways. Biochem Biophys Res Commun. 2009:383:475-9.

35. Asahi M, Asahi K, Jung JC, del Zoppo GJ, Fini ME, Lo EH. Role for matrix metalloproteinase 9 after focal cerebral ischemia: effects of gene knockout and enzyme inhibition with BB-94. J Cereb Blood Flow Metab. 2000;20:1681-9.

36. Bell RD, Winkler EA, Singh I, Sagare AP, Deane R, Wu Z, et al. Apolipoprotein E controls cerebrovascular integrity via cyclophilin A. Nature. 2012;485:512-6.

37. Dhanda S, Sandhir R. Blood-brain barrier permeability is exacerbated in experimental model of hepatic encephalopathy via MMP-9 activation and downregulation of tight junction proteins. Mol Neurobiol. 2018;55:3642-59.

38. Cheung AT, Messé SR. Preventing brain injury after cardiopulmonary bypass will require more than just dialing up the pressure. Circulation. 2018;137:1781-3.

Key Words: cold-inducible RNA-binding protein, hypothermia, cardiopulmonary bypass, blood-brain barrier 
TABLE E1. Physiologic variables and blood gas analyses during cardiopulmonary bypass

\begin{tabular}{|c|c|c|c|c|c|c|c|c|c|c|c|}
\hline Group & Time point & Weight, $g$ & MAP, mm Hg & HR, bpm & Het & $\mathrm{Hb}, \mathrm{g} / \mathrm{L}$ & pHa & Lac, mmol/L & $\mathrm{SaO}_{2}, \%$ & $\mathrm{PaO}_{2}, \mathrm{~mm} \mathrm{Hg}$ & $\mathrm{PaCO}_{2}, \mathrm{~mm} \mathrm{Hg}$ \\
\hline \multirow[t]{4}{*}{ Sham } & T0 & $330.21 \pm 13.53$ & $122.31 \pm 12.31$ & $375.02 \pm 8.02$ & $0.395 \pm 0.02$ & $132.2 \pm 5.7$ & $7.37 \pm 0.04$ & $0.91 \pm 0.15$ & $99.90 \pm 0.00$ & $491.04 \pm 37.73$ & $43.83 \pm 5.09$ \\
\hline & $\mathrm{T} 1$ & & $126.11 \pm 3.57$ & $420.84 \pm 25.45$ & $0.360 \pm 0.04$ & $120.0 \pm 14.7$ & $7.48 \pm 0.01$ & $0.97 \pm 0.25$ & $99.81 \pm 0.16$ & $394.30 \pm 47.34$ & $37.40 \pm 1.35$ \\
\hline & $\mathrm{T} 2$ & & $120.69 \pm 15.05$ & $439.26 \pm 69.64$ & $0.357 \pm 0.04$ & $119.0 \pm 14.7$ & $7.52 \pm 0.09$ & $1.60 \pm 0.20$ & $99.89 \pm 0.12$ & $362.90 \pm 42.52$ & $38.13 \pm 0.78$ \\
\hline & $\mathrm{T} 3$ & & $118.95 \pm 7.56$ & $414.06 \pm 49.07$ & $0.337 \pm 0.02$ & $112.3 \pm 5.5$ & $7.56 \pm 0.15$ & $1.67 \pm 0.47$ & $99.77 \pm 0.20$ & $339.27 \pm 22.52$ & $40.13 \pm 3.65$ \\
\hline \multirow[t]{4}{*}{$\mathrm{CPB}$} & T0 & $329.00 \pm 14.53$ & $124.31 \pm 14.33$ & $398.45 \pm 28.60$ & $0.390 \pm 0.03$ & $130.0 \pm 8.9$ & $7.32 \pm 0.06$ & $0.93 \pm 0.25$ & $99.77 \pm 0.23$ & $399.30 \pm 123.64$ & $45.16 \pm 1.95$ \\
\hline & $\mathrm{T} 1$ & & $85.43 \pm 17.07^{*}$ & $346.38 \pm 31.77^{*}$ & $0.189 \pm 0.03^{*}$ & $63.3 \pm 8.7 *$ & $7.51 \pm 0.04$ & $1.79 \pm 0.80$ & $97.90 \pm 0.37$ & $304.30 \pm 47.34$ & $37.27 \pm 20.50$ \\
\hline & $\mathrm{T} 2$ & & $79.98 \pm 14.31 *$ & $308.52 \pm 40.08^{*}$ & $0.203 \pm 0.02 *$ & $67.6 \pm 7.2^{*}$ & $7.58 \pm 0.01$ & $2.44 \pm 1.46$ & $99.90 \pm 0.20$ & $248.80 \pm 53.52$ & $37.05 \pm 12.26$ \\
\hline & $\mathrm{T} 3$ & & $104.61 \pm 21.12$ & $369.15 \pm 37.27$ & $0.203 \pm 0.02 *$ & $67.8 \pm 5.5^{*}$ & $7.57 \pm 0.04$ & $2.70 \pm 1.10 *$ & $99.80 \pm 0.17$ & $239.37 \pm 22.52 *$ & $34.62 \pm 12.41$ \\
\hline \multirow[t]{4}{*}{$\operatorname{Cirp}^{-1-}$} & T0 & $333.31 \pm 13.09$ & $125.16 \pm 16.68$ & $385.02 \pm 22.04$ & $0.403 \pm 0.01$ & $134.3 \pm 4.0$ & $7.36 \pm 0.01$ & $0.73 \pm 0.47$ & $99.90 \pm 0.12$ & $391.04 \pm 47.74$ & $47.26 \pm 3.45$ \\
\hline & $\mathrm{T} 1$ & & $87.73 \pm 14.27 *$ & $335.84 \pm 25.33^{*}$ & $0.197 \pm 0.02 *$ & $66.3 \pm 6.7^{*}$ & $7.54 \pm 0.15$ & $1.69 \pm 0.92$ & $98.07 \pm 1.17$ & $298.62 \pm 123.91$ & $33.02 \pm 17.53$ \\
\hline & $\mathrm{T} 2$ & & $82.71 \pm 12.22^{*}$ & $301.26 \pm 79.64 *$ & $0.204 \pm 0.03^{*}$ & $68.3 \pm 8.8^{*}$ & $7.57 \pm 0.11$ & $2.64 \pm 1.46$ & $99.07 \pm 0.58$ & $234.37 \pm 76.60$ & $32.05 \pm 9.13$ \\
\hline & $\mathrm{T} 3$ & & $113.95 \pm 5.56$ & $344.06 \pm 59.07$ & $0.204 \pm 0.02 *$ & $68.6 \pm 8.6^{*}$ & $7.59 \pm 0.69$ & $3.07 \pm 1.60 *$ & $98.96 \pm 1.21$ & $254.17 \pm 52.53^{*}$ & $38.03 \pm 8.21$ \\
\hline
\end{tabular}


TABLE E2. Differentially expressed genes between the CPB and $\mathrm{Cirp}^{-1-}$ group

\begin{tabular}{|c|c|c|c|c|}
\hline ID & Gene name & $\log _{2}$ fold change & $P$ value & padj \\
\hline ENSRNOG00000049743 & NEWGENE_620381 & 5.756687 & $2.60 \mathrm{E}-25$ & $5.91 \mathrm{E}-21$ \\
\hline ENSRNOG00000008428 & Drd2 & 5.236001 & $2.42 \mathrm{E}-24$ & $2.75 \mathrm{E}-20$ \\
\hline ENSRNOG00000011207 & Gh1 & -10.9314 & $1.31 \mathrm{E}-22$ & $9.93 \mathrm{E}-19$ \\
\hline novel.3609 & - & 4.622191 & $1.34 \mathrm{E}-20$ & $7.62 \mathrm{E}-17$ \\
\hline ENSRNOG00000028356 & LOC103694872 & 4.36004 & $6.93 \mathrm{E}-20$ & $3.15 \mathrm{E}-16$ \\
\hline ENSRNOG00000049580 & Gpr6 & 4.575496 & $1.27 \mathrm{E}-19$ & $4.83 \mathrm{E}-16$ \\
\hline ENSRNOG00000003800 & Rgs9 & 4.50444 & $1.63 \mathrm{E}-19$ & $5.22 \mathrm{E}-16$ \\
\hline ENSRNOG00000006589 & LOC103694877 & -4.45155 & $1.83 \mathrm{E}-19$ & $5.22 \mathrm{E}-16$ \\
\hline novel.12386 & - & 6.613628 & $3.54 \mathrm{E}-19$ & $8.96 \mathrm{E}-16$ \\
\hline novel.17638 & - & -4.44188 & $2.17 \mathrm{E}-18$ & $4.94 \mathrm{E}-15$ \\
\hline ENSRNOG00000008943 & Penk & 4.063058 & $2.83 \mathrm{E}-18$ & $5.86 \mathrm{E}-15$ \\
\hline ENSRNOG00000052099 & LOC103694869 & 5.457769 & $2.44 \mathrm{E}-16$ & $4.63 \mathrm{E}-13$ \\
\hline ENSRNOG00000007374 & Tac1 & 3.840393 & $2.69 \mathrm{E}-16$ & $4.71 \mathrm{E}-13$ \\
\hline novel.14959 & - & 3.945332 & $4.33 \mathrm{E}-16$ & 7.04E-13 \\
\hline novel.7447 & - & 4.094205 & $4.70 \mathrm{E}-16$ & 7.13E-13 \\
\hline ENSRNOG00000026679 & $\operatorname{Scn} 4 b$ & 3.671938 & $9.05 \mathrm{E}-16$ & $1.29 \mathrm{E}-12$ \\
\hline ENSRNOG00000023688 & Drd1 & 4.144552 & $2.83 \mathrm{E}-15$ & $3.79 \mathrm{E}-12$ \\
\hline novel.6887 & - & -4.73698 & $3.30 \mathrm{E}-15$ & 4.17E-12 \\
\hline ENSRNOG00000012556 & Isl1 & 6.639481 & $7.65 \mathrm{E}-15$ & $8.74 \mathrm{E}-12$ \\
\hline ENSRNOG00000046250 & LOC100911027 & -4.26365 & $7.68 \mathrm{E}-15$ & $8.74 \mathrm{E}-12$ \\
\hline novel.1668 & - & -6.74895 & $8.99 \mathrm{E}-15$ & $9.74 \mathrm{E}-12$ \\
\hline ENSRNOG00000028404 & Ppp1r1b & 3.461061 & $1.85 \mathrm{E}-14$ & $1.92 \mathrm{E}-11$ \\
\hline ENSRNOG00000049944 & LOC100911440 & -3.55439 & $2.70 \mathrm{E}-14$ & 2.67E-11 \\
\hline ENSRNOG00000025037 & Ankk1 & 9.538262 & $2.89 \mathrm{E}-14$ & $2.74 \mathrm{E}-11$ \\
\hline ENSRNOG00000049298 & LOC100909595 & -4.27853 & $5.71 \mathrm{E}-14$ & $5.20 \mathrm{E}-11$ \\
\hline ENSRNOG00000054508 & Foxp2 & 3.745592 & $1.92 \mathrm{E}-13$ & $1.68 \mathrm{E}-10$ \\
\hline novel.6691 & - & 3.518378 & $4.03 \mathrm{E}-13$ & $3.39 \mathrm{E}-10$ \\
\hline novel.3607 & - & 4.514926 & $4.50 \mathrm{E}-13$ & $3.66 \mathrm{E}-10$ \\
\hline ENSRNOG00000025012 & Chat & 5.12503 & $7.89 \mathrm{E}-13$ & $6.19 \mathrm{E}-10$ \\
\hline ENSRNOG00000018780 & Sh3rf2 & 5.112869 & $9.25 \mathrm{E}-13$ & $7.02 \mathrm{E}-10$ \\
\hline ENSRNOG00000002462 & LOC108348055 & 3.811961 & $1.75 \mathrm{E}-12$ & $1.29 \mathrm{E}-09$ \\
\hline ENSRNOG00000018736 & Pnpla2 & -4.24752 & $2.36 \mathrm{E}-12$ & $1.68 \mathrm{E}-09$ \\
\hline novel.9466 & - & 4.759742 & $2.56 \mathrm{E}-12$ & 1.77E-09 \\
\hline novel.10387 & - & 3.548767 & $4.04 \mathrm{E}-12$ & $2.71 \mathrm{E}-09$ \\
\hline ENSRNOG00000050855 & LOC100911994 & 3.806039 & $8.10 \mathrm{E}-12$ & $5.27 \mathrm{E}-09$ \\
\hline novel.9329 & - & -3.5714 & $8.34 \mathrm{E}-12$ & $5.27 \mathrm{E}-09$ \\
\hline ENSRNOG00000047618 & LOC100910196 & 4.597373 & $1.73 \mathrm{E}-11$ & $1.06 \mathrm{E}-08$ \\
\hline ENSRNOG00000046120 & RGD1561252 & -3.75616 & 2.92E-11 & $1.75 \mathrm{E}-08$ \\
\hline ENSRNOG00000011542 & Apopt1 & 3.520596 & $3.62 \mathrm{E}-11$ & $2.11 \mathrm{E}-08$ \\
\hline novel.12385 & - & 8.893641 & $4.50 \mathrm{E}-11$ & $2.56 \mathrm{E}-08$ \\
\hline ENSRNOG00000011824 & Trh & 3.337768 & $6.41 \mathrm{E}-11$ & $3.56 \mathrm{E}-08$ \\
\hline ENSRNOG00000003209 & Pcp411 & 2.89843 & $8.38 \mathrm{E}-11$ & $4.54 \mathrm{E}-08$ \\
\hline ENSRNOG00000045949 & LOC100911581 & -3.40651 & $8.76 \mathrm{E}-11$ & 4.63E-08 \\
\hline ENSRNOG00000048130 & LOC100911725 & -5.21115 & $1.62 \mathrm{E}-10$ & $8.40 \mathrm{E}-08$ \\
\hline
\end{tabular}


TABLE E2. Continued

\begin{tabular}{|c|c|c|c|c|}
\hline ID & Gene name & $\log _{2}$ fold change & $P$ value & padj \\
\hline ENSRNOG00000028041 & Tnnt1 & 3.218826 & $2.63 \mathrm{E}-10$ & $1.33 \mathrm{E}-07$ \\
\hline novel.7455 & - & 3.156254 & $2.86 \mathrm{E}-10$ & $1.41 \mathrm{E}-07$ \\
\hline novel.6266 & - & 8.72119 & $2.96 \mathrm{E}-10$ & $1.43 \mathrm{E}-07$ \\
\hline ENSRNOG00000010053 & Calcr & 5.754447 & $3.13 \mathrm{E}-10$ & $1.48 \mathrm{E}-07$ \\
\hline novel.17647 & - & 5.732464 & $4.00 \mathrm{E}-10$ & $1.86 \mathrm{E}-07$ \\
\hline ENSRNOG00000061943 & Rn60_7_1214.2 & -4.47812 & $4.08 \mathrm{E}-10$ & $1.86 \mathrm{E}-07$ \\
\hline ENSRNOG00000050827 & Pdcd5 & -2.9381 & $5.20 \mathrm{E}-10$ & $2.32 \mathrm{E}-07$ \\
\hline ENSRNOG00000022946 & Slc22a3 & 4.115772 & $5.50 \mathrm{E}-10$ & $2.39 \mathrm{E}-07$ \\
\hline ENSRNOG00000007112 & Pcsk1n & -3.60924 & $5.57 \mathrm{E}-10$ & $2.39 \mathrm{E}-07$ \\
\hline ENSRNOG00000055229 & LOC108348118 & -4.4434 & $5.95 \mathrm{E}-10$ & $2.51 \mathrm{E}-07$ \\
\hline ENSRNOG00000014761 & Rasd2 & 2.693744 & 7.41E-10 & $3.06 \mathrm{E}-07$ \\
\hline ENSRNOG00000049495 & Krt71 & 3.040058 & $8.14 \mathrm{E}-10$ & $3.31 \mathrm{E}-07$ \\
\hline ENSRNOG00000016000 & LOC100911417 & 2.741865 & $1.49 \mathrm{E}-09$ & $5.96 \mathrm{E}-07$ \\
\hline ENSRNOG00000037188 & Mug1 & 5.568427 & $1.84 \mathrm{E}-09$ & $7.23 \mathrm{E}-07$ \\
\hline novel.3942 & - & -4.33395 & $1.91 \mathrm{E}-09$ & $7.35 \mathrm{E}-07$ \\
\hline novel.17965 & - & 3.149788 & $2.02 \mathrm{E}-09$ & $7.65 \mathrm{E}-07$ \\
\hline ENSRNOG00000010478 & LOC500712 & 5.543393 & $2.40 \mathrm{E}-09$ & $8.96 \mathrm{E}-07$ \\
\hline ENSRNOG00000001701 & $\mathrm{Cbr} 3$ & 2.796487 & $2.55 \mathrm{E}-09$ & $9.35 \mathrm{E}-07$ \\
\hline ENSRNOG00000008356 & Myo5c & 3.283644 & $3.15 \mathrm{E}-09$ & $1.14 \mathrm{E}-06$ \\
\hline novel.9369 & - & 4.077866 & $6.45 \mathrm{E}-09$ & $2.29 \mathrm{E}-06$ \\
\hline ENSRNOG00000012038 & Htrld & 4.696278 & $8.28 \mathrm{E}-09$ & $2.90 \mathrm{E}-06$ \\
\hline ENSRNOG00000055934 & Dmkn & 3.234468 & $1.44 \mathrm{E}-08$ & $4.95 \mathrm{E}-06$ \\
\hline novel.10141 & - & 4.000001 & $1.50 \mathrm{E}-08$ & $5.11 \mathrm{E}-06$ \\
\hline ENSRNOG00000009530 & Uchl3 & 3.260809 & $1.69 \mathrm{E}-08$ & $5.65 \mathrm{E}-06$ \\
\hline novel.70 & - & -4.10877 & $1.87 \mathrm{E}-08$ & $6.15 \mathrm{E}-06$ \\
\hline novel.107 & - & -8.31898 & $2.10 \mathrm{E}-08$ & $6.81 \mathrm{E}-06$ \\
\hline ENSRNOG00000049491 & RT1-DMb & -4.06376 & $2.89 \mathrm{E}-08$ & $9.25 \mathrm{E}-06$ \\
\hline ENSRNOG00000050602 & Kif $28 p$ & 8.226635 & $2.93 \mathrm{E}-08$ & $9.25 \mathrm{E}-06$ \\
\hline ENSRNOG00000019473 & NEWGENE_1582994 & -3.19466 & $5.48 \mathrm{E}-08$ & $1.71 \mathrm{E}-05$ \\
\hline novel.18207 & - & 2.551516 & $5.71 \mathrm{E}-08$ & $1.75 \mathrm{E}-05$ \\
\hline novel.11466 & - & -5.31473 & $7.22 \mathrm{E}-08$ & $2.19 \mathrm{E}-05$ \\
\hline novel.913 & - & 2.480194 & $7.98 \mathrm{E}-08$ & $2.39 \mathrm{E}-05$ \\
\hline ENSRNOG00000002151 & LOC103693564 & -8.15904 & $8.20 \mathrm{E}-08$ & $2.42 \mathrm{E}-05$ \\
\hline novel.17330 & - & 3.784693 & $1.12 \mathrm{E}-07$ & $3.27 \mathrm{E}-05$ \\
\hline ENSRNOG00000026371 & Krt17 & 4.43387 & $1.15 \mathrm{E}-07$ & $3.31 \mathrm{E}-05$ \\
\hline ENSRNOG00000009143 & Lrrc57 & -3.56108 & $1.74 \mathrm{E}-07$ & $4.96 \mathrm{E}-05$ \\
\hline ENSRNOG00000011310 & Pde10a & 2.657965 & $1.84 \mathrm{E}-07$ & $5.16 \mathrm{E}-05$ \\
\hline ENSRNOG00000010822 & Dlx6 & 2.688737 & $2.30 \mathrm{E}-07$ & $6.39 \mathrm{E}-05$ \\
\hline novel.17289 & - & 2.263178 & $2.39 \mathrm{E}-07$ & $6.55 \mathrm{E}-05$ \\
\hline ENSRNOG00000009735 & Fibcd1 & -4.4691 & $2.67 \mathrm{E}-07$ & $7.24 \mathrm{E}-05$ \\
\hline ENSRNOG00000040201 & Atp6ap11 & 2.583491 & $3.08 \mathrm{E}-07$ & $8.26 \mathrm{E}-05$ \\
\hline novel. 18225 & - & -3.19674 & $3.30 \mathrm{E}-07$ & $8.74 \mathrm{E}-05$ \\
\hline ENSRNOG00000045760 & Ebna1bp2 & 2.926169 & $3.41 \mathrm{E}-07$ & $8.92 \mathrm{E}-05$ \\
\hline novel.11413 & - & 2.326483 & $3.52 \mathrm{E}-07$ & $9.09 \mathrm{E}-05$ \\
\hline
\end{tabular}


TABLE E2. Continued

\begin{tabular}{|c|c|c|c|c|}
\hline ID & Gene name & $\log _{2}$ fold change & $P$ value & padj \\
\hline novel.10511 & - & 4.960079 & $4.78 \mathrm{E}-07$ & 0.000122185 \\
\hline novel.1048 & - & 7.896671 & $5.06 \mathrm{E}-07$ & 0.000127933 \\
\hline novel.15609 & - & -2.50346 & $6.82 \mathrm{E}-07$ & 0.000170436 \\
\hline novel.16165 & - & 2.638777 & $7.44 \mathrm{E}-07$ & 0.000183948 \\
\hline ENSRNOG00000018250 & Tnni3 & 2.951473 & 7.87E-07 & 0.000192516 \\
\hline novel.17838 & - & 4.882351 & $9.27 \mathrm{E}-07$ & 0.000224341 \\
\hline ENSRNOG00000062141 & Slc18a3 & 2.517415 & $1.09 \mathrm{E}-06$ & 0.000258229 \\
\hline ENSRNOG00000058862 & AABR07051308.1 & 7.800873 & $1.09 \mathrm{E}-06$ & 0.000258229 \\
\hline ENSRNOG00000021555 & Mis18a & -2.83549 & $1.38 \mathrm{E}-06$ & 0.000324878 \\
\hline ENSRNOG00000002229 & Adcy 5 & 2.063366 & $1.47 \mathrm{E}-06$ & 0.000340775 \\
\hline novel.14186 & - & -7.77357 & $1.61 \mathrm{E}-06$ & 0.000370791 \\
\hline ENSRNOG00000003171 & $\mathrm{Mpz}$ & 3.756283 & $1.66 \mathrm{E}-06$ & 0.000378378 \\
\hline novel.259 & - & 2.02752 & $2.06 \mathrm{E}-06$ & 0.00046441 \\
\hline ENSRNOG00000012302 & Gucy $1 \mathrm{a} 3$ & 2.041653 & $2.10 \mathrm{E}-06$ & 0.000468072 \\
\hline ENSRNOG00000027894 & Iqgap3 & 2.296892 & $2.20 \mathrm{E}-06$ & 0.000486914 \\
\hline ENSRNOG00000060949 & Anxa8 & 7.698259 & $2.40 \mathrm{E}-06$ & 0.000525986 \\
\hline ENSRNOG00000025889 & Gnas & 3.272291 & $2.52 \mathrm{E}-06$ & 0.000541813 \\
\hline ENSRNOG00000045772 & LOC100911545 & 3.272291 & $2.52 \mathrm{E}-06$ & 0.000541813 \\
\hline ENSRNOG00000046192 & Nsun4 & -3.80989 & 2.92E-06 & 0.000621263 \\
\hline ENSRNOG00000007647 & Oprk1 & 2.427701 & $3.37 \mathrm{E}-06$ & 0.000710423 \\
\hline ENSRNOG00000038370 & Ahsg & 7.644078 & $3.61 \mathrm{E}-06$ & 0.000752787 \\
\hline ENSRNOG00000001369 & Oas1a & -4.17303 & 4.01E-06 & 0.000823146 \\
\hline ENSRNOG00000003119 & $\mathrm{Gc}$ & 4.000788 & 4.01E-06 & 0.000823146 \\
\hline ENSRNOG00000057060 & LOC108348049 & -2.91718 & 4.84E-06 & 0.000984419 \\
\hline ENSRNOG00000024848 & Fga & 7.587783 & $5.45 \mathrm{E}-06$ & 0.001087 \\
\hline ENSRNOG00000003566 & Apoh & 7.587783 & $5.45 \mathrm{E}-06$ & 0.001087 \\
\hline novel.12981 & - & 2.307147 & $5.80 \mathrm{E}-06$ & 0.00114807 \\
\hline ENSRNOG00000002802 & Cxcl1 & -2.49077 & $6.32 \mathrm{E}-06$ & 0.001239602 \\
\hline ENSRNOG00000019985 & Asic4 & 1.946177 & $6.48 \mathrm{E}-06$ & 0.001259617 \\
\hline novel.14040 & - & 3.590771 & $6.96 \mathrm{E}-06$ & 0.001341588 \\
\hline ENSRNOG00000033613 & RGD1565459 & 4.620359 & $7.53 \mathrm{E}-06$ & 0.001440588 \\
\hline ENSRNOG00000015267 & Aldh18a1 & 2.995367 & $7.68 \mathrm{E}-06$ & 0.001456248 \\
\hline ENSRNOG00000017374 & Prl & -7.53376 & $8.28 \mathrm{E}-06$ & 0.001557509 \\
\hline novel.9533 & - & 3.518856 & $9.35 \mathrm{E}-06$ & 0.001743561 \\
\hline ENSRNOG00000019719 & Kcna5 & 2.584711 & $1.04 \mathrm{E}-05$ & 0.00191662 \\
\hline novel.11870 & - & -2.20459 & $1.20 \mathrm{E}-05$ & 0.002194958 \\
\hline novel.4379 & - & -7.46702 & $1.27 \mathrm{E}-05$ & 0.002257673 \\
\hline ENSRNOG00000046980 & LOC108348151 & 7.468141 & $1.27 \mathrm{E}-05$ & 0.002257673 \\
\hline novel.71 & - & 1.88223 & $1.27 \mathrm{E}-05$ & 0.002257673 \\
\hline novel.18705 & - & 2.446084 & $1.27 \mathrm{E}-05$ & 0.002257673 \\
\hline ENSRNOG00000009371 & Abl1 & 2.299046 & $1.32 \mathrm{E}-05$ & 0.002303517 \\
\hline ENSRNOG00000050660 & Grcc10 & -2.30709 & $1.32 \mathrm{E}-05$ & 0.002303517 \\
\hline ENSRNOG00000024330 & Ngp & -2.57653 & $1.33 \mathrm{E}-05$ & 0.002317368 \\
\hline ENSRNOG00000021225 & Oxt & 2.851458 & $1.41 \mathrm{E}-05$ & 0.002431351 \\
\hline
\end{tabular}


TABLE E2. Continued

\begin{tabular}{|c|c|c|c|c|}
\hline ID & Gene name & $\log _{2}$ fold change & $P$ value & padj \\
\hline ENSRNOG00000060572 & Tlk1 & 2.576805 & $1.48 \mathrm{E}-05$ & 0.002529312 \\
\hline ENSRNOG00000010597 & Slc5a7 & 1.967894 & $1.65 \mathrm{E}-05$ & 0.002798929 \\
\hline novel.11984 & - & 2.749849 & $1.66 \mathrm{E}-05$ & 0.002802539 \\
\hline ENSRNOG00000033026 & Dclk3 & 1.866587 & $1.74 \mathrm{E}-05$ & 0.002910833 \\
\hline ENSRNOG00000018257 & Нpx & 2.899361 & $1.78 \mathrm{E}-05$ & 0.002961488 \\
\hline ENSRNOG00000010440 & Gnal & 1.829045 & $1.88 \mathrm{E}-05$ & 0.003108202 \\
\hline ENSRNOG00000055705 & LOC103694905 & -7.39704 & $1.96 \mathrm{E}-05$ & 0.003205799 \\
\hline novel.6068 & - & 2.336162 & $2.01 \mathrm{E}-05$ & 0.003270511 \\
\hline ENSRNOG00000018613 & Crip3 & 3.792127 & $2.06 \mathrm{E}-05$ & 0.003318338 \\
\hline novel.6089 & - & -2.00019 & $2.08 \mathrm{E}-05$ & 0.003327142 \\
\hline novel.77 & - & 2.036851 & $2.30 \mathrm{E}-05$ & 0.0036328 \\
\hline ENSRNOG00000008644 & Nkx2-1 & 2.480539 & $2.30 \mathrm{E}-05$ & 0.0036328 \\
\hline novel. 8248 & - & 1.776533 & $2.93 \mathrm{E}-05$ & 0.00460042 \\
\hline ENSRNOG00000012315 & Agmat & 2.845384 & $3.04 \mathrm{E}-05$ & 0.004683547 \\
\hline novel.15258 & - & -7.32349 & $3.05 \mathrm{E}-05$ & 0.004683547 \\
\hline novel.15492 & - & 7.337672 & $3.05 \mathrm{E}-05$ & 0.004683547 \\
\hline
\end{tabular}

padj, Adjusted $P$ value. 